\title{
Seasonal Predictability of Extratropical Storm Tracks in GFDL's High-Resolution Climate Prediction Model
}

\author{
Xiaosong Yang, ${ }^{*}$ Gabriel A. Vecchi, ${ }^{+}$Rich G. Gudgel, ${ }^{\#}$ Thomas L. Delworth, ${ }^{+}$Shaoding Zhang, ${ }^{\text {}}$

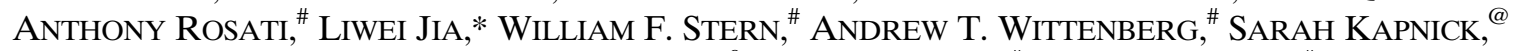 \\ RYM MSADEK, * SETH D. UNDERWOOD, ${ }^{\&}$ FANRONG ZENG, ${ }^{\#}$ WHIT ANDERSON, ${ }^{\#}$ AND \\ VENKATRAMANI BALAJI ${ }^{+}$ \\ * NOAA/Geophysical Fluid Dynamics Laboratory, Princeton, New Jersey, and University Corporation for \\ Atmospheric Research, Boulder, Colorado \\ ${ }^{+}$NOAA/Geophysical Fluid Dynamics Laboratory, and Atmospheric and Oceanic Sciences Program, \\ Princeton University, Princeton, New Jersey \\ \# NOAA/Geophysical Fluid Dynamics Laboratory, Princeton, New Jersey \\ @ Atmospheric and Oceanic Sciences Program, Princeton University, Princeton, New Jersey \\ \& Dynamics Research Corporation, Andover, Massachusetts
}

(Manuscript received 23 July 2014, in final form 10 December 2014)

\begin{abstract}
The seasonal predictability of extratropical storm tracks in the Geophysical Fluid Dynamics Laboratory's (GFDL)'s high-resolution climate model has been investigated using an average predictability time analysis. The leading predictable components of extratropical storm tracks are the ENSO-related spatial patterns for both boreal winter and summer, and the second predictable components are mostly due to changes in external radiative forcing and multidecadal oceanic variability. These two predictable components for both seasons show significant correlation skill for all leads from 0 to 9 months, while the skill of predicting the boreal winter storm track is consistently higher than that of the austral winter. The predictable components of extratropical storm tracks are dynamically consistent with the predictable components of the upper troposphere jet flow for both seasons. Over the region with strong storm-track signals in North America, the model is able to predict the changes in statistics of extremes connected to storm-track changes (e.g., extreme low and high sea level pressure and extreme 2-m air temperature) in response to different ENSO phases. These results point toward the possibility of providing skillful seasonal predictions of the statistics of extratropical extremes over land using high-resolution coupled models.
\end{abstract}

\section{Introduction}

The extratropical storm tracks are regions of frequent baroclinic waves and associated surface cyclones and anticyclones. These storms are characterized by strong winds and heavy precipitation, and are thus a source of regional extreme weather and climate events. Additionally, the poleward transport of heat, momentum, and moisture associated with midlatitude storms is a prominent part of the global circulation system. Thus, predicting and projecting future changes of storm tracks is of huge societal and scientific interest.

Corresponding author address: Xiaosong Yang, NOAA/ Geophysical Fluid Dynamics Laboratory, 201 Forrestal Rd., Princeton, NJ 08540.

E-mail: xiaosong.yang@noaa.gov
Extratropical storm tracks vary on seasonal, interannual, and decadal-to-centennial time scales (Chang et al. 2002; E. K. M. Chang et al. 2013; Stockdale et al. 2011). On interannual time scales, storm tracks exhibit not only a fluctuation of intensity as well as north-south shifts associated with atmospheric internal mode variability (Lau 1988; Yang and Chang 2006, 2007), but also changes in response to El Niño-Southern Oscillation (ENSO) cycle. During El Niño years, the Pacific storm track shifts equatorward and downstream (Straus and Shukla 1997; Zhang and Held 1999; Eichler and Higgins 2006), while La Niña events drive a shift in the opposite direction. The dynamics of the midlatitude storm tracks' response to ENSO involve extratropical response to local enhancement of the Hadley circulation over the eastern Pacific (Bjerknes 1969), and there are feedbacks from ENSOinduced storm-track changes that play an important role in controlling the extratropical response to ENSO 
(Held et al. 1989). The Northern Hemisphere winter storm tracks also exhibit interdecadal variations (Chang and Fu 2002). On centennial time scales, the CMIP3 and CMIP5 models project poleward migration and intensification of the Southern Hemisphere storm tracks in the twenty-first century in response to greenhouse gas changes (Chang et al. 2012; E. K. M. Chang et al. 2013). The observational, theoretical, and modeling aspects of the extratropical storm tracks on multiple time scales have been extensively studied in the literature [see the review paper by Chang et al. (2002)], but what has not been assessed as broadly is the extent to which dynamical models can predict seasonal storm-track variations.

State-of-the-art dynamical seasonal prediction systems have demonstrated skill in forecasting oceanic and land surface temperature and precipitation in the hindcasts (e.g., Saha et al. 2006; Jia et al. 2015), and the routine seasonal forecasts using dynamical climate models are provided to society and policy makers by the worldwide operational forecasting centers (Saha et al. 2006, 2014; Merryfield et al. 2013; Stockdale et al. 2011). The useful products derived from the seasonal forecasts have been limited to the first moment of variables of interest, such as the seasonal mean land surface temperature and precipitation, but the predictability of the second moment of variables of interest, such as the variance statistics of extratropical storm tracks, has not been explored. The second moment of a variable contains detailed distribution beyond the simple mean, especially for the information related to extreme climate and weather events. Assessment of the predictability of the second moment statistics would potentially enrich the seasonal forecast information from the mean to higher order and therefore provide more detailed information for the users. In addition, examining the storm-track predictability is a measure of model fidelity, since storm tracks are symbiotically linked to the planetary-scale flow (Cai and Mak 1990). In this study, we evaluate the predictability of extratropical storm tracks in GFDL's high-resolution seasonal prediction system, which has been shown to provide skillful seasonal forecasts of land surface temperature and precipitation (Jia et al. 2015), tropical cyclones (Vecchi et al. 2014), and Arctic sea ice extent (Msadek et al. 2014a).

In this study, we employ a method called average predictability time (APT) optimization (DelSole and Tippett 2009a,b; DelSole et al. 2011) to identify the predictable patterns of storm tracks in the seasonal hindcasts. The APT has been used for identifying an internal interdecadal predictable pattern of sea surface temperature in GFDL's decadal hindcasts (Yang et al. 2013) and is capable of distinguishing the ENSO-driven seasonal signals from anthropogenic forced response of land surface temperature in GFDL's seasonal hindcasts (Jia et al. 2015). Our main goals are to identify the predictable patterns of storm tracks in the hindcasts using APT, assess the predictive skill of those patterns, and understand the mechanisms responsible for that predictability. Details of the hindcasts and observational datasets are discussed in section 2. The methodology is reviewed in section 3 . In section 4 , the predictable patterns for storm tracks are identified by APT analysis, the retrospective predictive skill is assessed using observations, and the role of mean flow predictability in stormtrack prediction is investigated. Conclusions and discussions are given in section 5 .

\section{Model, hindcast experiments, and observations}

The high-resolution climate model explored here, FLOR (forecast-oriented low-resolution version of GFDL CM2.5), is a combination of two previously described GFDL coupled model configurations, namely CM2.1 (Delworth et al. 2006) and CM2.5 (Delworth et al. 2012). The atmosphere and land models have an approximately $50 \mathrm{~km} \times 50 \mathrm{~km}$ spatial resolution, and are those used in CM2.5 (Delworth et al. 2012), which have ocean models at a $0.25^{\circ} \times 0.25^{\circ}$ resolution. The ocean and sea ice components of the model are at $1^{\circ} \times 1^{\circ}$ resolution, based on those of CM2.1, which has been used extensively for climate research, predictions, and projections for close to a decade. In this climate model, the ocean component has been slightly altered from that of CM2.1 by incorporating a newer, higher-order advection scheme, an updated parameterization for eddies (Farneti et al. 2010), a more realistic representation of the solar absorption by the ocean, and a biharmonic horizontal viscosity scheme. FLOR has most of its computational expense and resolution concentrated in the atmosphere and land components. A detailed description of the FLOR model can be found in Vecchi et al. (2014).

The seasonal hindcasts were initialized using the GFDL's ensemble coupled data assimilation (ECDA) system. The ECDA employs an ensemble-based filtering algorithm applied to the CM2.1. More details of the ECDA can be found in Zhang et al. (2007) and Zhang and Rosati (2010). The ECDA covers the period from 1960 to present and is being updated monthly for GFDL's seasonal-to-decadal experimental forecasts (Yang et al. 2013; Vecchi et al. 2013; Msadek et al. 2014b). A comprehensive assessment of the 1960-2010 oceanic variability in the latest version of the ECDA can be found in Y.-S. Chang et al. (2013). Note that the initial conditions of different components of FLOR are taken from different available sources at GFDL, since the data assimilation system for FLOR is under development (Vecchi et al. 2014). The initial conditions 
for the ocean and ice components of the FLOR hindcasts are taken from the ECDA, while the initial conditions for the atmosphere and land components are taken from FLOR atmosphere-only simulations driven by observed SSTs. The 12-member ensemble seasonal hindcasts were initialized on the first day every month from 1982 to 2014 and integrated for 12 months with temporally varying anthropogenic and natural forcing. The seasonal hindcast anomalies for each variable were obtained by subtracting out the lead-time-dependent climatology from hindcasts. For the historical forcing simulations, the five ensemble members using FLOR were integrated using temporally varying anthropogenic and natural forcing from 1860 to 2013. Note that the temporally varying anthropogenic and natural forcings between 1982 to 2014 are exactly the same for the historical forcing simulations and seasonal hindcasts.

The observational data used in this study are the sea level pressure (SLP), 2-m air temperature, 10-m wind speeds, and 300-hPa zonal winds and precipitation from the ERA-Interim reanalysis of the European Center for Medium-Range Weather Forecasts (ECMWF) (Dee et al. 2011). The Niño-3.4 index, the average SST anomalies in the region bounded by $5^{\circ} \mathrm{N}-5^{\circ} \mathrm{S}, 170^{\circ}-$ $120^{\circ} \mathrm{W}$, is calculated from the United Kingdom Meteorological Office Hadley Centre Sea Ice and Sea Surface Temperature dataset (HadISST 1.1) analyses (Rayner et al. 2003). A rainy day is defined as a day with the daily precipitation exceeding $1 \mathrm{~mm} \mathrm{day}^{-1}$ based on the recommendation of the World Meteorological Organization (Klein Tank et al. 2009).

The statistical significance test of the anomaly correlation coefficients (ACC) between observations and hindcasts is formed by the null hypothesis that ACC is 0 , and we perform this test by determining whether the confidence interval for ACC contains 0 . If the $95 \%$ confidence interval for ACC does not contain 0, we conclude that ACC is significant at the $5 \%$ significant level.

\section{Review of methodology}

\section{a. Storm-track statistics}

To highlight synoptic time-scale variability, seasonal standard deviation statistics are computed using a 24-h difference filter (Wallace et al. 1988), as follows:

$$
\operatorname{std}=\sqrt{\frac{1}{N} \sum_{t=1}^{N}[v(t+24 \mathrm{~h})-v(t)]^{2}},
$$

where $N$ is the sample size of each season, and $v$ is a variable representing the storm-track activity. As discussed in previous studies (Chang and Fu 2002), this filter has half power points at periods of 1.2 and 6 days, and results obtained based on this filter are very similar to those obtained using other commonly used bandpass filters. Many different variables are commonly used to measure storm-track activity, such as the meridional winds in different vertical levels, 500-hPa geopotential height, and SLP (Chang et al. 2002, 2012). Here we use SLP for computing the storm-track statistics, since our interest is in the surface storm tracks. We compute the seasonal storm-track indices using (1) from 6-hourly SLP for both model hindcasts and ERA-Interim reanalysis. We only focus on the winter seasons of December-February (DJF) for the Northern Hemisphere (NH) and July-September (JAS) for the Southern Hemisphere (SH). Instead of using conventional JuneAugust (JJA) months representing the Southern Hemisphere winter, JAS is used because of its stronger split jet mean flow than JJA (Yang and Chang 2006) and its stronger field significance of ENSO-teleconnected global temperature and precipitation patterns than JJA (Yang and DelSole 2012).

\section{b. The average predictability time analysis}

We employ the average predictability time optimization method to identify characteristic patterns of predictable components in the seasonal hindcasts. Complete details of APT can be found in DelSole and Tippett (2009a,b). Briefly, the method is to maximize APT, which is defined as the integral over lead time of the "signal to total" variance ratio of a forecast model:

$$
\mathrm{APT}=2 \int_{0}^{\infty} \frac{\sigma_{\text {signal }}^{2}(\tau)}{\sigma_{\text {total }}^{2}} d \tau,
$$

where $\sigma_{\text {signal }}^{2}(\tau)$ is the variance of the ensemble mean at fixed lead time $\tau$, and $\sigma_{\text {total }}^{2}$ is the corresponding total variance of the forecast ensemble. For the ensemble forecasts, the signal and total covariance can be approximated by the corresponding ensemble covariances. Following DelSole and Tippett (2009a), maximizing APT in ensemble forecasts leads to the generalized eigenvalue problem

$$
\left[2 \sum_{\tau=1}^{L} \boldsymbol{\Sigma}_{\text {signal }}(\tau)\right] \mathbf{q}=\lambda \boldsymbol{\Sigma}_{\text {total }} \mathbf{q},
$$

where $L$ is the maximum forecast lead time, $\mathbf{q}$ is the desired projection vector, $\boldsymbol{\Sigma}_{\text {signal }}(\tau)$ is the ensemble mean covariance matrix at the forecast lead time $\tau$, and $\boldsymbol{\Sigma}_{\text {total }}$ is the total ensemble covariance matrix. The eigenvectors $\mathbf{q}$ provide the basis for decomposing the 
multivariate time series into a complete, uncorrelated set of components ordered such that the first maximizes APT, the second maximizes APT subject to being uncorrelated with the first, and so on. The eigenvalues of (3) correspond to the APT values of each component. This decomposition based on APT is analogous to empirical orthogonal function (EOF) analysis, except that we decompose predictability instead of decomposing variance.

For solving the APT optimization problem (3) in practice, the data are first projected onto the leading principal components (PCs) (DelSole et al. 2011). We have a relatively long sample size of 3960 (i.e., 33 initial conditions, 12 ensemble members, and 10 lead times), so the time series and patterns from APT are virtually independent of the number of PCs in the range of 20-40 PCs (not shown). We choose 30 PCs for displaying results for both SLP and 300-hPa zonal wind in the following.

Following DelSole et al. (2011), the statistical significance test of APT was estimated by Monte Carlo methods. The null hypothesis for the test is that the data are drawn from a white noise process. Accordingly, we generated a $30 \times 3960$ data matrix by drawing independent random numbers from a normal distribution with zero mean and unit variance. The time dimension of the data was grouped as a set of 30 separate 10-season forecasts with 12 ensemble members each; 30 APT values were then determined. This procedure was repeated 1000 times to generate $1000 \times 30$ APT values. The 95 th percentile of the $1000 \times 30$ APT values was then determined as the threshold values for statistical significance.

\section{Results}

\section{a. Mean flow and storm-track climatology}

Since midlatitude storm tracks interact with the largescale mean flow through the wave-mean flow interactions, we first examine the model's capability of reproducing the observed climatological mean flow and storm tracks. Figure 1 shows mean 300 -hPa zonal winds for DJF and JAS in observations and FLOR hindcasts. The pattern anomaly correlation coefficient and rootmean-square error between hindcasts and observations are 0.98 and $2.6 \mathrm{~m} \mathrm{~s}^{-1}$ respectively for DJF, and 0.98 and $2.8 \mathrm{~m} \mathrm{~s}^{-1}$ respectively for JAS. The high spatial correlation coefficients indicate that the model is able to reproduce the geographic features of the observed climatological $300-\mathrm{hPa}$ zonal winds in both seasons. Compared to observations, the hindcasts reasonably simulate the location and intensity of the North AfricaEast Asia jet, the North Pacific jet, and the North Atlantic jet in the DJF season. The remarkable zonal asymmetry of the DJF jet intensity in the Southern Ocean (i.e., the weaker jet stream in the South Pacific and the stronger jet in the south Indian Ocean and South Atlantic) is well reproduced in the hindcasts. In the JAS season, the model reproduces the observed location and intensity of jets in the North Pacific and the North Atlantic. It is worth noting that the split structure of the Southern Hemisphere winter jet is faithfully reproduced by the model (i.e., the model reproduces the strong subtropical jet extending from the central south Indian Ocean across Australia to the east-central South Pacific Ocean between $20^{\circ}$ and $40^{\circ} \mathrm{S}$, the polar front jet concentrated along $60^{\circ} \mathrm{S}$ in the South Pacific, and a zone of weak westerlies centered in New Zealand).

The spatial pattern of errors for DJF and JAS are shown in Figs. 1b and 1e respectively. For DJF, it is dominantly a dipole pattern with westerly errors on the equatorward side of the dipole. The dipole is present in both hemispheres but is particularly pronounced in the Northern Hemisphere with errors exceeding $6 \mathrm{~m} \mathrm{~s}^{-1}$, while it is considerably smaller in amplitude for the Southern Hemisphere. For JAS, the large westerly errors exceeding $4 \mathrm{~m} \mathrm{~s}^{-1}$ are generally confined within the equatorward side of the westerly jet. The zonal mean errors, shown in Figs. 1c and 1f, exhibit a gradual increase with lead time for both seasons.

Figure 2 shows mean storm tracks for DJF and JAS in observations and FLOR hindcasts. The spatial rootmean-square errors between hindcasts and observations are 0.5 and $0.9 \mathrm{hPa}$ for DJF and JAS respectively. The spatial anomaly correlation coefficients between hindcasts and observations are 0.99 and 0.98 for DJF and JAS respectively, suggesting the strong agreement between these two climatological fields. In the DJF season, the location, orientation, and intensity of the North Pacific, North American, North Atlantic, and Eurasian continental storm tracks as well as the Southern Hemisphere storm tracks are well simulated by the model, although the maxima of the North Pacific, North Atlantic, and South Pacific storm tracks in the model are generally weaker than those in observations. In the JAS season, consistent with reproducing the split jet seen in Fig. 1, the model is capable of reproducing the observed location and intensity of the South Atlantic and southern Indian Ocean storm tracks and the poleward migration of the South Pacific storm tracks.

The spatial patterns of storm-track errors for DJF and JAS are shown in Figs. $2 b$ and 2e respectively. For DJF, it is dominant of a dipole pattern in high latitudes with negative errors over the North Pacific and Atlantic storm tracks and positive errors over the North Pole. For JAS, the model generally has a positive bias. The errors are particularly strong over the Antarctic continent with 

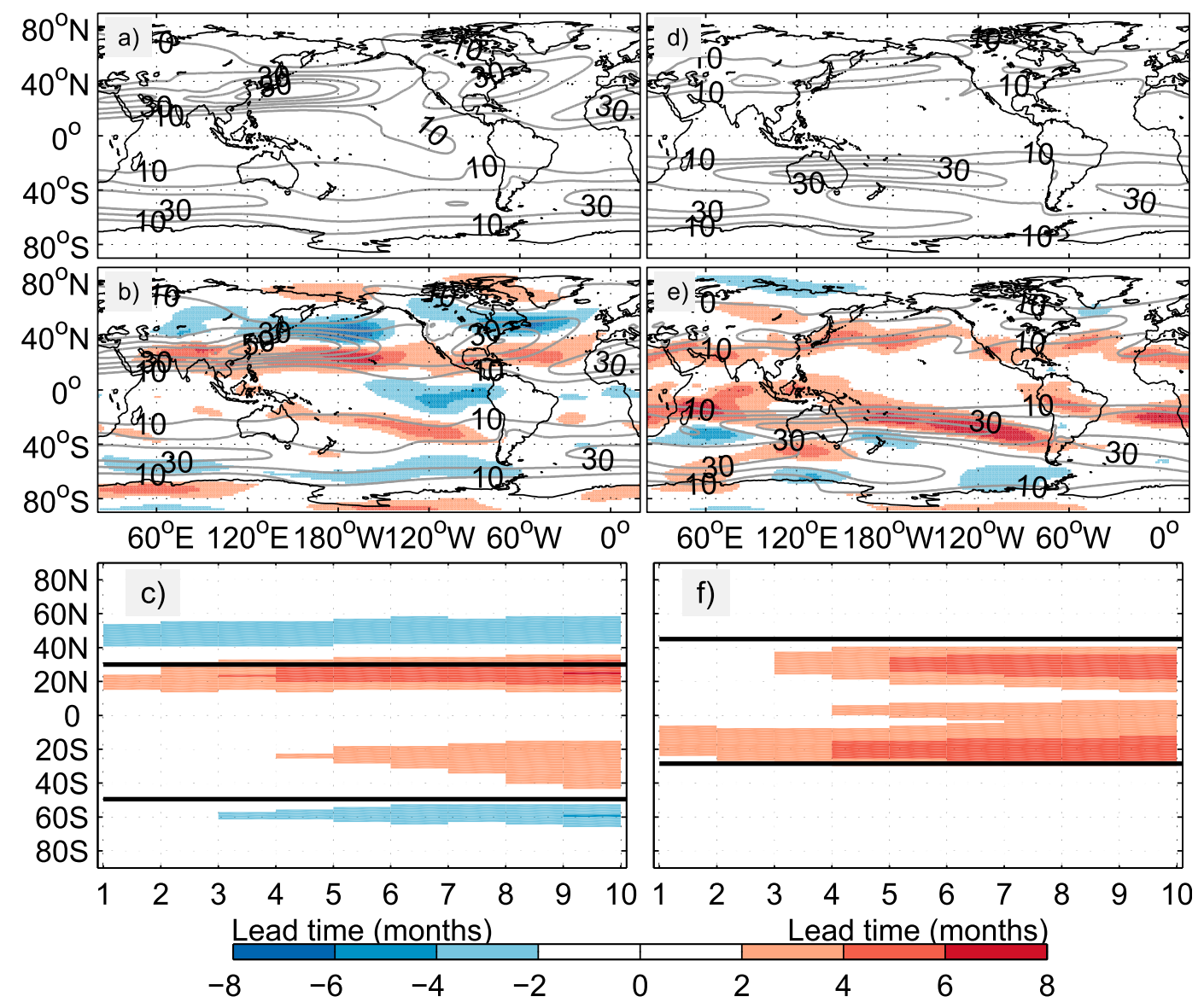

FIG. 1. The climatological 300-hPa zonal winds for DJF in (a) model and (b) observation; and for JAS in (d) model and (e) observation. The difference between model and observation is color shaded for (b) and (e), and the zonal mean of the difference is shown as a function of lead time for (c) DJF and (f) JAS. The contour interval is $10 \mathrm{~m} \mathrm{~s}^{-1}$ in (a),(b),(d), and (e), and the shading interval is $2 \mathrm{~m} \mathrm{~s}^{-1}$ in (b),(c),(e), and (f). The heavy solid lines in (c) and (f) denote the observational maximum jet position.

errors exceeding $2 \mathrm{hPa}$, while the errors for the Northern Hemisphere are relatively weaker. The zonal mean errors, shown in Figs. $2 \mathrm{c}$ and $2 \mathrm{f}$, exhibit weaker dependence with lead time for both seasons in comparison with the errors of $300-\mathrm{hPa}$ zonal winds. Note that the lead-time-dependent model biases were removed for the skill verification by subtracting out the lead-timedependent climatology from hindcasts.

\section{b. Predictable patterns of storm tracks}

We first apply APT analysis to the storm tracks for the DJF and JAS seasons. The APT values for the two seasons are shown in Fig. 3. Based on the Monte Carlo statistical test described in section $3 b$, the first three components have statistically significant APT values for both DJF and JAS. However, only the two leading components have multiseason predictive skill verified against observations, so we only focus on the two leading components in this study. Note that the fraction of global variance explained by each predictable component for both seasons is generally lower than about $10 \%$; however, it will be shown later that the leading components can explain a significant amount of variance in certain geographic locations.

\section{1) THE DJF SEASON}

The component with the maximum APT for the DJF season is shown in Fig. 4a. The pattern generally shows an equatorward shift of the North Pacific and North Atlantic storm tracks and the South Atlantic and Indian Ocean storm tracks, with weakening of the North American and the South Pacific storm tracks. Note that the amplitude of the pattern is considerably larger in North America (over $0.7 \mathrm{hPa}$ ) than elsewhere. The APT value for this component is 14.7 months, and the fraction of global variance explained by this component is about $7.8 \%$ (Fig. 3). The spatial distribution of the fraction of variance explained by the leading component is shown 


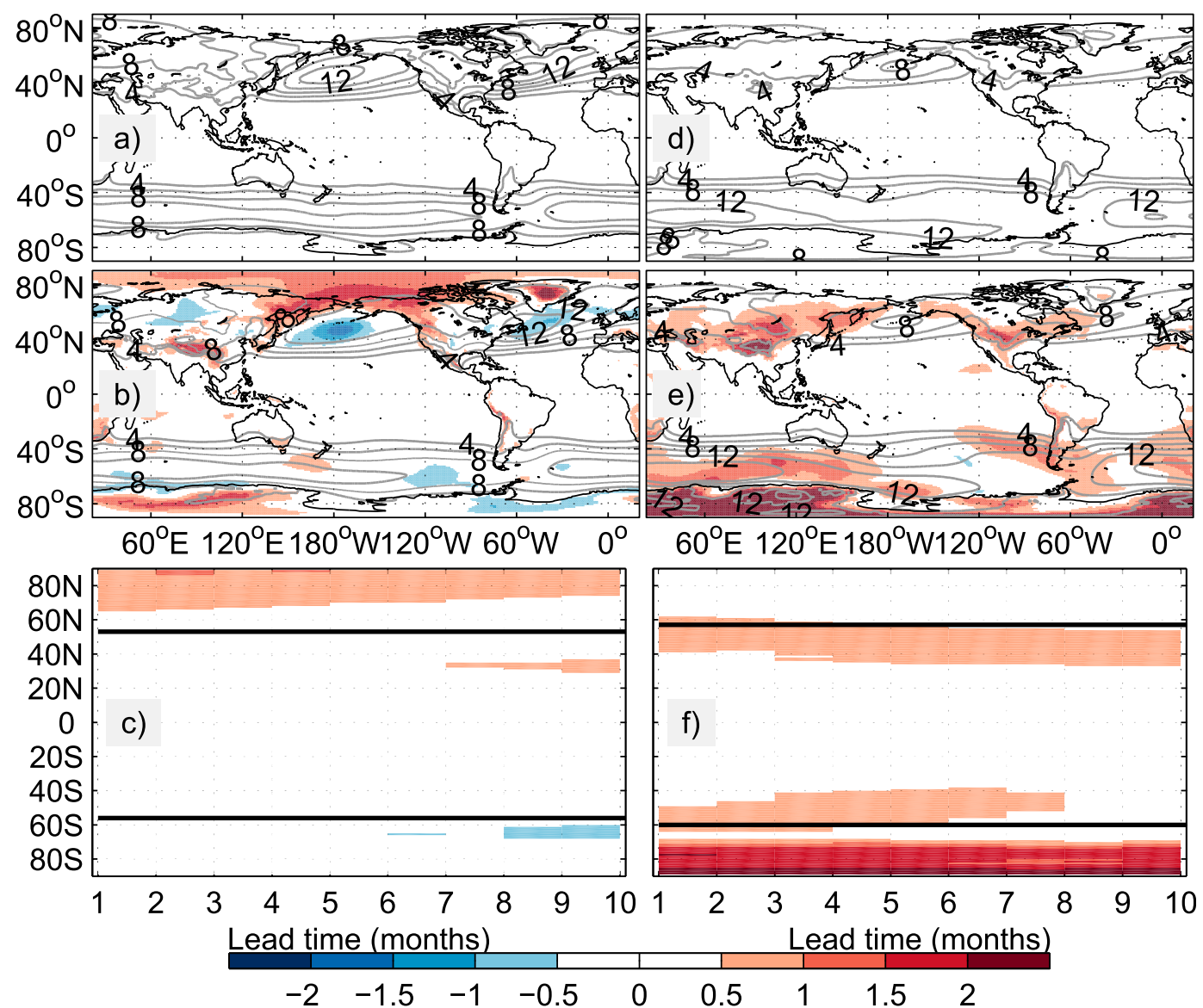

FIG. 2. The climatological storm tracks measured by the standard deviation of 24-h-difference filtered sea level pressures for DJF in (a) model hindcasts and (b) observation; and for JAS in (d) model hindcasts and (e) observation. The difference between model and observation is shaded for (b) and (e), and the zonal mean of the difference is shown as a function of lead time for (c) DJF and (f) JAS. The contour interval is $2 \mathrm{hPa}$ in (a),(b),(d), and (e), and the shading interval is $0.5 \mathrm{hPa}$ in (b),(c),(e), and (f). The heavy solid lines in (c) and (f) denote the observational stormtrack axis position.

in Fig. 4b. We see that the leading predictable component explains as much as $35 \%$ of the variance in North America, and $15 \%$ of the variance in the southern Atlantic and Pacific Oceans. These results show that the leading predictable components explain a significant amount of variance in certain geographic locations.

The time series of the leading component as a function of initialized years from 1982 to 2014 are shown in Fig. 4c for lead times of 1-5 and 6-10 months, respectively. To assess the forecast skill of the component, we project the ERA-Interim data onto the eigenvector $\mathbf{q}$ with maximum APT from (3) to obtain the observed time series, which are indicated by the solid black line in Fig. 4c. The observed time series is highly correlated with the observed Niño-3.4 index with the correlation coefficient of 0.79 , suggesting this pattern is ENSO-related. The ACC between forecasts and observations as a function of initial months, shown in Fig. 4d, generally decrease with the lead time, but are statistically significant up to 9 months of lead time at $5 \%$ significance level. The skill of predicting this storm-track pattern is generally lower than the skill of predicting ENSO itself (Fig. 4c), but they have a similar pattern over the initial months: a sharp decrease of ACC starting from early summer (June) to early spring (March) initial conditions. The decrease in predictability over the summer is consistent with the known "spring barrier" of predicting ENSO and ENSOrelated land temperature and precipitation patterns (Barnston et al. 2012; Jia et al. 2015).

The leading predictable pattern of the storm-track variability is consistent with the ENSO-teleconnected storm-track patterns reported in previous modeling and observational studies (Straus and Shukla 1997; Zhang and Held 1999; Eichler and Higgins 2006). The advance of this study is that not only is the ENSO-related pattern successfully identified in seasonal hindcasts using APT 

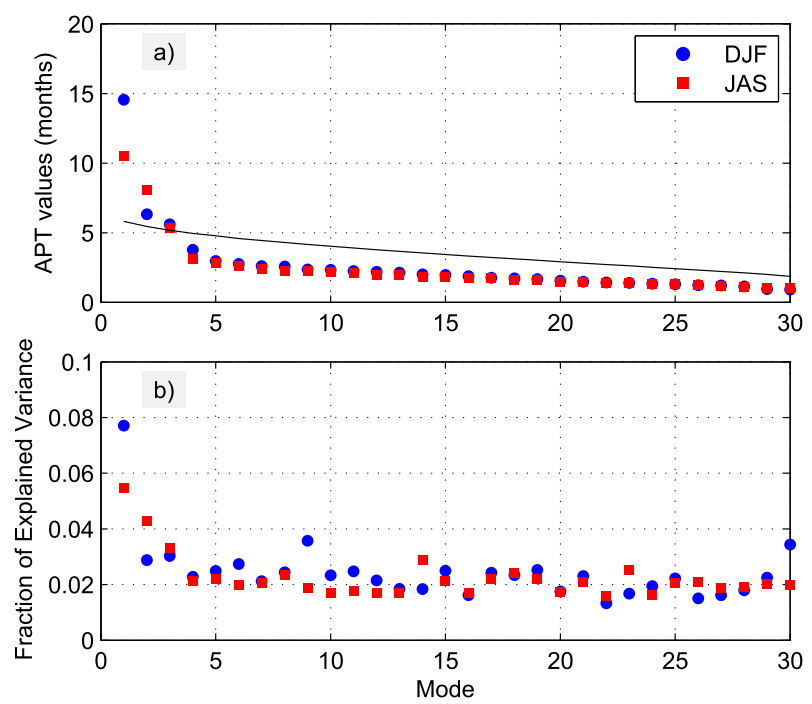

FIG. 3. (a) The APT values and (b) the associated fraction of explained variance using 30 leading PCs for the 24-h difference filtered SLP in DJF and JAS. Solid line is the 5\% significance level of the APT values.

analysis, but also this pattern as a whole may be retrospectively predictable up to 9 months in advance at the $5 \%$ significance level in GFDL's fully coupled highresolution seasonal forecasting system.

The second predictable component $(\mathrm{PrC} 2)$ for the DJF seasonal hindcasts, shown in Fig. 5a, generally shows a poleward shift and strengthening of the $\mathrm{SH}$ storm tracks and weakening of the North Atlantic storm tracks. The APT value for this component is 6.4 months, and the fraction of global variance explained by this component is about $2.8 \%$. The spatial distribution of the fraction of variance explained by $\mathrm{PrC} 2$ is shown in Fig. $5 \mathrm{~b}$. We see that PrC2 explains as much as $12.5 \%$ of the variance in the middle and high latitudes of Southern Oceans. These results show that $\mathrm{PrC} 2$ explains comparable amount of variance in certain geographic locations to that of $\operatorname{PrC} 1$. The time series of this component as a function of initialized years from 1982 to 2014 are shown in Fig. $5 \mathrm{c}$ for lead times of $1-5$ and $6-10$ months, respectively. The ACC between forecasts and observations as a function of initial months, shown in Fig. 5d, are statistically significant up to 9 months of lead time at the $5 \%$ significance level, but independent of the lead time.

The time series of the PrC2 in the DJF season exhibits a multidecadal increasing trend in the hindcasts as well as observations (Fig. 5c), and the associated pattern in the Southern Hemisphere bears remarkable similarity to the linear trend pattern in FLOR's historical forcing experiment (Fig. 6a), suggesting that the signal in the Southern Hemisphere is mostly the response to the changes in external radiative forcings. The pattern is also consistent with CMIP5 models' projections of poleward expansion and strengthening of the Southern Hemisphere storm track at the surface (Chang et al. 2012). However, the weakening of the North Atlantic storm track is opposite to the linear trend pattern in the historical forcing experiment, and we speculate that it may be linked to the Atlantic multidecadal oscillation (AMO) phase transition from cold to warm in the last 30 years, since the warm phase of AMO tends to weaken the North Atlantic storm track (Zhang and Delworth 2007). Thus, both the radiative forcing and multidecadal oceanic variability could contribute to the seasonal predictability of the DJF storm tracks.

\section{2) THE JAS SEASON}

The pattern of the PrC1 for the JAS seasonal hindcasts, shown in Fig. 7a, generally shows a poleward shift of the South Atlantic storm tracks, a tripole structure with weakening of storm-track activity between $40^{\circ}$ and $60^{\circ} \mathrm{S}$, and strengthening between $30^{\circ}$ and $40^{\circ} \mathrm{S}$ in the South Pacific and the west Antarctic continent. The APT value for this component is 10.5 months, and the fraction of global JAS variance explained by this component is about $5.5 \%$. This component explains as much as $25 \%$ of the variance in the South Pacific Ocean (Fig. 7b), suggesting its significant contribution of predictability in certain geographic locations.

The time series of the leading APT mode as a function of initialized years from 1982 to 2014 are shown in Fig. 7c for lead times of 1-5 and 6-10 months, respectively. Like the DJF PrC1, the observed time series of the JAS PrC1 is highly correlated with the observed Niño-3.4 index with a correlation coefficient of 0.82 , suggesting this pattern is ENSO-related. The ACC between forecasts and observations as a function of lead time, shown in Fig. 7d, generally show a sharp decrease from June to February initial conditions for both PrC1 and Niño-3.4 index, although they are significant at 5\% significance level over all the lead times. Again, this is likely related to the spring barrier of ENSO prediction. Compared with the DJF season, the skill of predicting the $\operatorname{PrC} 1$ and ENSO in JAS is consistently lower at each lead time.

The ENSO-related storm-track pattern is consistent with the observed Antarctic dipole mode associated with ENSO (Yuan 2004). Note that the maximum amplitude center of the pattern locates in the zone where the climatological jet and storm tracks are weaker than the surrounding area in the South Pacific (see Figs. 1 and 2), so the leading predictable pattern of the JAS storm track in the $\mathrm{SH}$ is distinct from the storm-track pattern associated with the leading atmospheric internal mode-the southern annular mode (Yang and Chang 2007). 

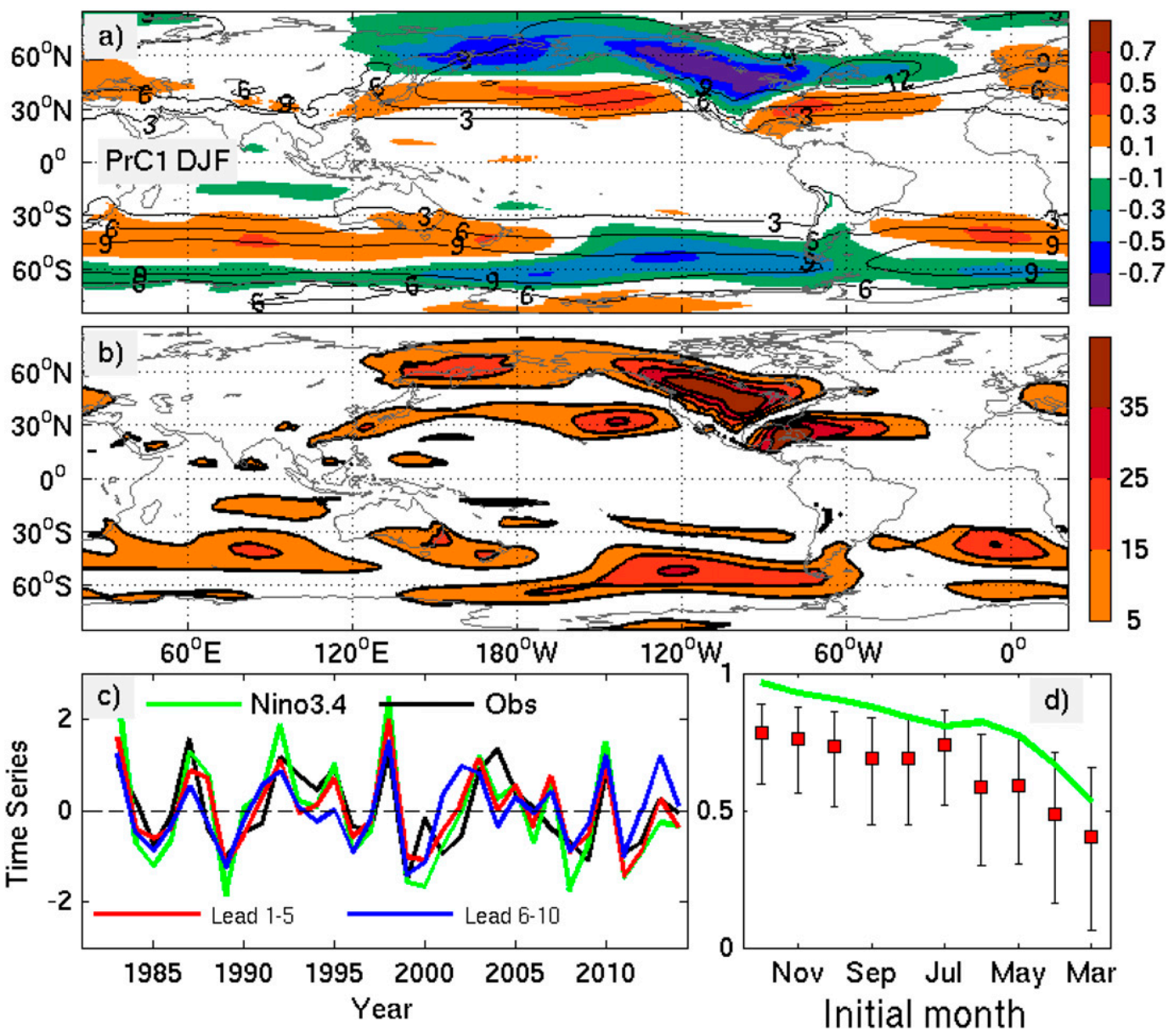

FIG. 4. (a) The spatial structure of the predictable component (color shading) that maximized the average predictability time of storm tracks in the seasonal hindcasts for the DJF season, which is called PrC1. The black contour denotes the climatological storm tracks (in $\mathrm{hPa}$ ). The shading unit is $\mathrm{hPa}$ per unit standard deviation. (b) Percent of variance of storm tracks explained by PrC1. (c) The ensemble mean time series of PrC1 averaged over lead time 0-4 months (red solid) and 5-9 months (blue solid) as a function of time; the time series of the ERAInterim data projected onto PrC1 (black solid), and the Niño-3.4 index (green solid) from 1982 to 2014. (d) The anomaly correlation coefficients (ACC) between forecasts and observations (red squares) and associated $95 \%$ error bars as a function of initial month. The green line denotes the ACC for the Niño-3.4 index.

The PrC2 for the JAS season, shown in Fig. 8a, generally shows a band of increase between $30^{\circ}$ and $70^{\circ} \mathrm{S}$ in the South Atlantic, south Indian Ocean, and western South Pacific. The APT value for this component is 8.1 months, and the fraction of explained variance by this component is about $4.3 \%$. The time series of this component as a function of initialized years from 1982 to 2014 are shown in Fig. 8 b for lead times of $1-5$ and $6-10$ months, respectively. The time series of the $\mathrm{PrC} 2$ in the JAS season exhibits a multidecadal increasing trend in the hindcasts as well as in the observations. The ACC between hindcasts and observations as a function of initial months, shown in Fig. 8c, are statistically significant at the $5 \%$ significance level for 6 out of 10 initial months.
The storm track pattern of the JAS PrC2 bears similarity with the linear trend pattern in the historical forcing experiment (Fig. 6b), but the amplitude is much stronger in the hindcasts than the historical forcing experiment, implying that this component is partly the response to the changes in external radiative forcings. In addition, the linear trend in the observed time series of the JAS PrC2 with a slope of 0.3 unit variate per decade is much weaker than the counterpart of the DJF PrC2 with a slope of 0.8 unit variateper decade (Figs. $5 \mathrm{~b}$ and $8 \mathrm{~b}$ ), resulting in the lower skill of predicting the trend pattern in JAS than DJF.

The above analysis based on APT identified predictable components with different time scales and mechanisms for the storm track (i.e., the ENSO-related 

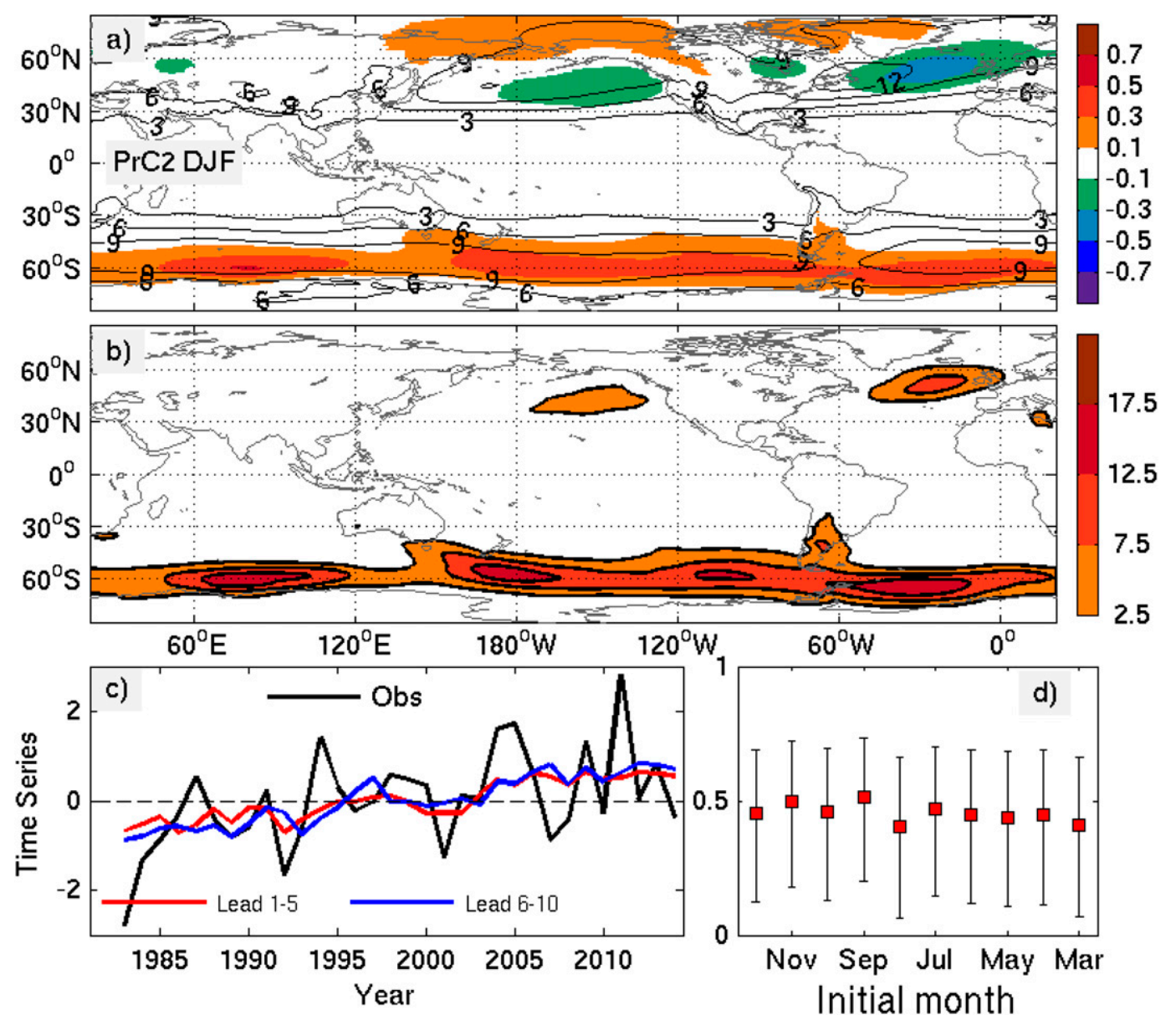

FIG. 5. (a) The spatial structure of the second predictable component (color shading, in hPa per unit standard deviation) that maximized the average predictability time of storm tracks in the hindcasts for the DJF season, which is called PrC2. The black contour denotes the climatological storm tracks (in hPa). (b) Percent of variance of storm tracks explained by PrC2. (c) The ensemble mean time series of PrC1 averaged over lead time 0-4 months (red solid) and 5-9 months (blue solid) as a function of time; and the time series of the ERA Interim data projected onto PrC1 (black solid). (d) The anomaly correlation coefficients (ACC) between forecasts and observations (red squares) and associated $95 \%$ error bars as a function of the forecast lead time.

component on interannual scales and the externally forced trend component on multidecadal scales) suggests that both the forced component and the unforced internal variability contribute to seasonal predictions of midlatitude storm tracks. This is consistent with the fact that seasonal predictions of land 2-m air temperature can be attributed to both the forced component and the unforced (i.e., ENSO) component relating to internal variability (Jia et al. 2015).

\section{3) RECONSTRUCTING PREDICTIONS FROM PREDICTABLE COMPONENTS}

APT is capable of decomposing raw hindcasts into predictable components (signal) and unpredictable components (noise), so we can reconstruct hindcasts based upon the predictable components while filtering out unpredictable components; thus, we expect improvement in predictive skill by the reconstruction. Here, we generate a reconstructed model using a small number of leading predictable components, and select the components if the corresponding APT values are statistically significant at the 5\% significance level. The first three components are chosen for the reconstructed model based on the Monte Carlo test for both DJF and JAS storm tracks (Fig. 3).

The geographic distribution of correlation skill between the 1-month lead raw hindcasts and observations for the DJF storm tracks, shown in Fig. 9a, displays strong skill over the North Pacific and North American regions and the midlatitudes in the Southern Hemisphere. The regions with large correlation coefficients are generally coincident with the large loading centers of 

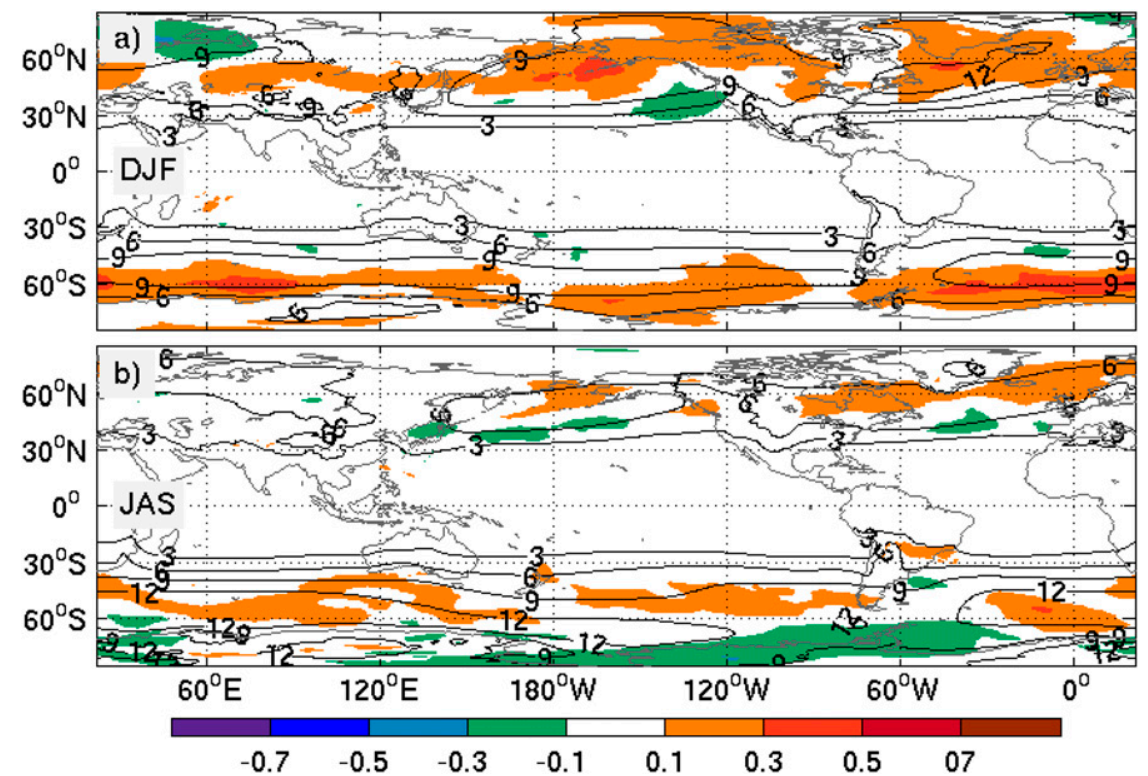

FIG. 6. The linear trend pattern of storm tracks (color shading) derived from the five-member historical forcing simulations of FLOR from 1981 to 2013 for the (a) DJF and (b) JAS seasons. The shading unit is hPa per unit standard deviation. The black contour denotes the climatological storm tracks (in $\mathrm{hPa}$ ).

the leading predictable components (see Figs. 4a and 5a). The correlation skill map for the reconstructed model, shown in Fig. 9b, exhibits a similar geographic distribution as the raw hindcasts, but with a higher degree of spatial coherence and a wider area of significant predictive skill than the raw hindcasts. To further quantitatively compare the predictive skill of the reconstructed model and the raw hindcasts, we show in Figs. 9c and 9d the percentage of grid points over the North Pacific and North America region $\left(25^{\circ}-75^{\circ} \mathrm{N}, 180^{\circ}-60^{\circ} \mathrm{W}\right)$ in each bin (interval of 0.05 ) for the anomaly correlation coefficients of reconstructed versus raw hindcasts at lead time 0-4 months and 5-9 months respectively. In the plot, a value above the diagonal line implies that the correlation coefficient of the reconstructed hindcasts is higher than that from the raw hindcasts. The overwhelming majority of points for correlation coefficients are above the diagonal line, and the ratio of the points above the diagonal line out of the total points is about $79 \%$ and $76 \%$ for the lead time $0-4$ months and 5-9 months respectively (Figs. 9c,d), indicating that the reconstructed model outperform the raw hindcasts. Note that the distribution pattern of correlation coefficients systematically shifts from larger values to smaller values as the lead time increases, indicating that the predictive skill degrades with increasing lead times. The improvement of predictive skill using reconstructed model based on leading predictable components was also found in the JAS storm-track hindcasts (not shown).
The skill analysis of the raw hindcasts further confirms the robustness of APT diagnosis for identifying the predictable signals. The fact that the reconstructed model outperforms the raw hindcasts indicates that the reconstructed model based on few predictable components may be used as a refinement model of raw hindcasts from a dynamical model. The improvement of storm-track predictive skill due to the APT refinement is consistent with the improvements of predictive skill for the seasonal land temperature and precipitation using the same technique (Jia et al. 2015).

\section{4) HindCAST FOR THE 2013/14 DJF SEASON}

The APT analysis finds features that systematically maximize the average predictability over all lead times, so the identified predictable components (e.g., the ENSO-related component and the multidecadal trend component) tend to persist over multiple seasons. However, there can be years that exhibit skill, even though the drivers of the APT features are not the principal sources of skill (e.g., in non-ENSO years). The 2013/14 DJF season provides an example of this, as it was not a classic ENSO year and the observed storm tracks over North America were enhanced (Fig. 10a). In 2013/14 DJF, there was a pronounced reduction of stormtrack activity over the North Pacific Ocean and the West Coast of the United States, and a substantial increase of storm-track activity extending from central Canada down to the Midwestern United States. This pattern 

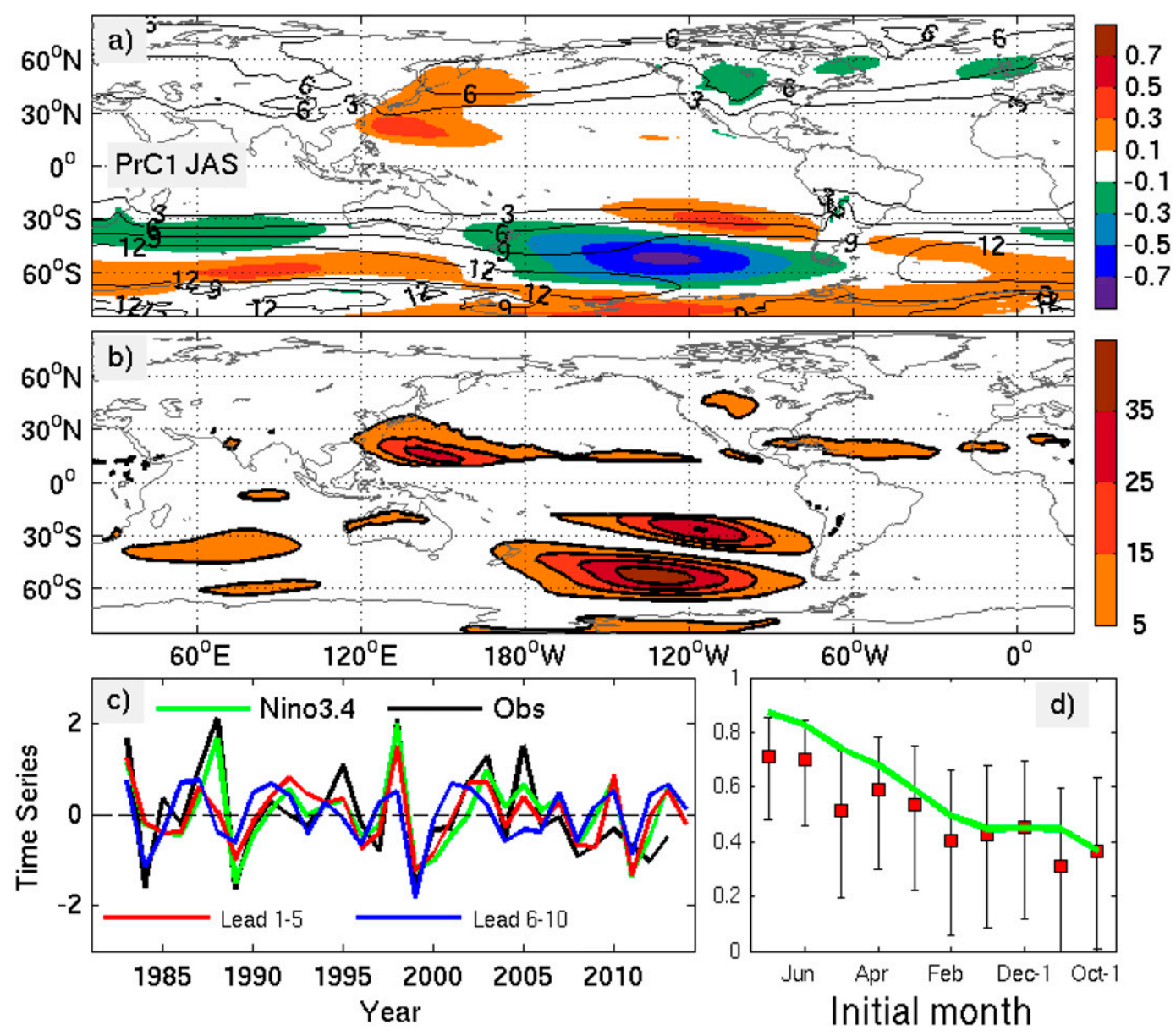

FIG. 7. As in Fig. 4, but for the JAS season.

differs from the classical cold ENSO pattern, and although the nominal Niño-3 anomalies in 2013/14 winter were cold, it did not exhibit canonical ENSO anomalies in the eastern tropical Pacific. Nevertheless, the FLOR hindcasts initialized on 1 November 2013 reproduce the principal aspects of the observed storm-track anomalies (Fig. 10b), although the ensemble mean amplitudes are much weaker than the observations. The ensemblemean hindcast is composed of some ensemble members that bear more and others less similarity to observations, with the ensemble mean showing the largest correlation with observation (Fig. 11). However, we show a "best" ensemble member that looks similar to observation by visual inspection in Fig. 10c. This member was able to reproduce the location and extreme amplitudes of the observed storm-track anomalies, indicating that the observed extreme anomalies were in the forecast spread. The ability of the ensemble mean to recover the large observed correlation indicates a predictable element to this particular winter's storm tracks, but the ensemble spread indicates that the extreme values involved a stochastic element. To further examine the relationship among forecast ensembles and observation, we plot the anomalies of each member and the ensemble mean and observations for one center of positive anomalies over the Midwestern North America and another center of negative anomalies in the North Pacific in Fig. 11. For both locations, the ensemble spreads are quite large while the observed anomalies are within the ensemble spread, suggesting that the uncertainty to the initial conditions is large and a sufficient ensemble size is required for retrieving the signal for this case.

We note that the hindcasts initialized on 1 October 2013 show less agreement with observations, and there is almost no skill for the hindcasts initialized on 1 September 2013 and earlier (not shown). Therefore, the skill for this year was limited to one to two months lead. A more detailed exploration of the mechanisms and sources of the predictability for this case is underway and, along with additional experiments, will be described in the future. 

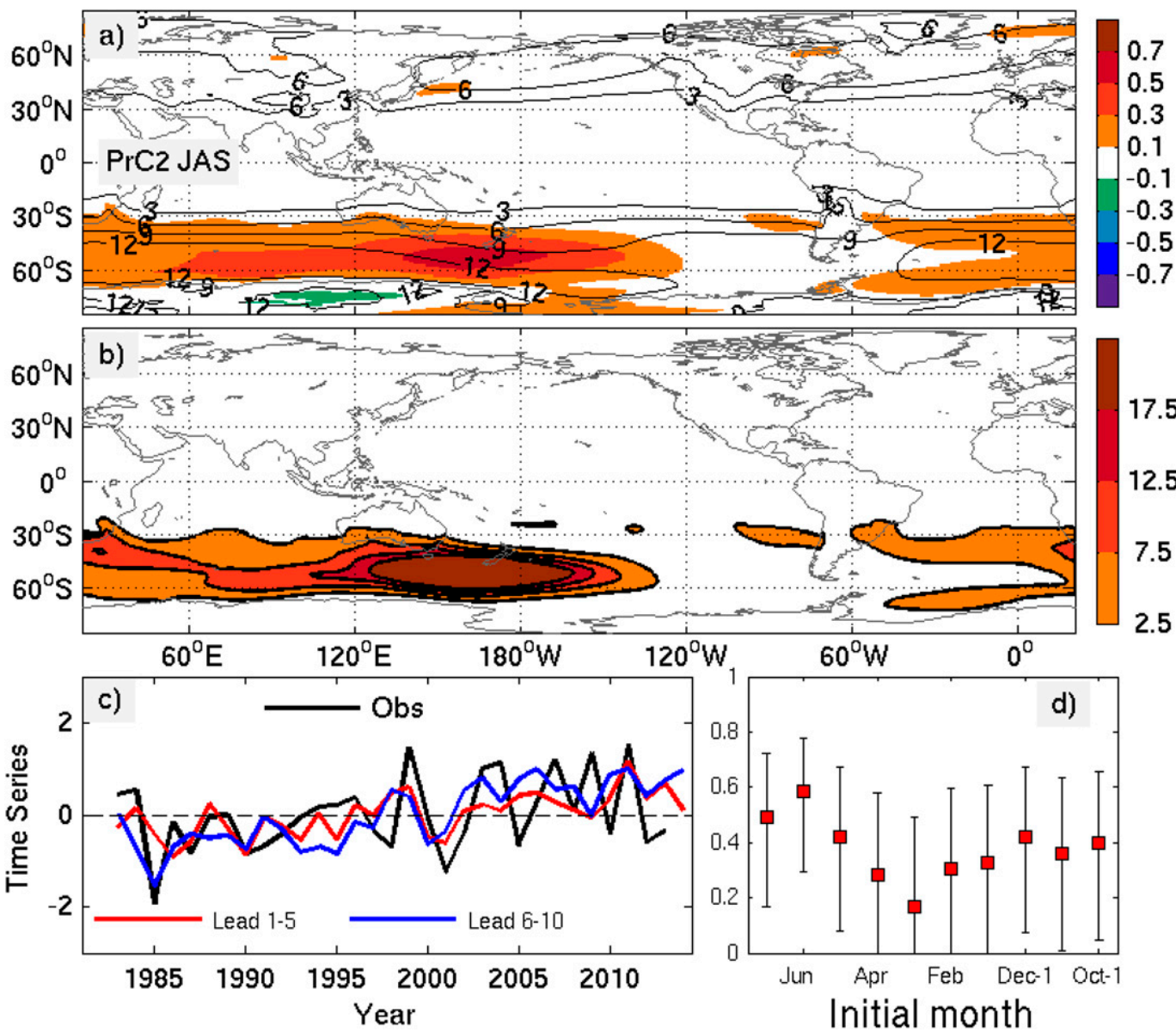

FIG. 8. As in Fig. 5, but for the JAS season.

\section{c. Roles of mean flow in storm-track predictability}

Midlatitude storm-track variations are symbiotically linked to the planetary-scale flow changes and their associated eddy-mean flow interactions (Cai and Mak 1990; Branstator 1995). The dynamical processes governing ENSO-induced storm-track predictability include representing the planetary-scale flow associated with anomalous tropical heating and the eddy-mean flow interactions (Held et al. 1989). In general, a corresponding shift in the storm-track structure will accompany an anomaly in the mean jet flow. We have shown that the ENSO-induced storm-track pattern is predictable up to multiple seasons in advance in the GFDL high-resolution prediction system. To further confirm that the predictive skill arises from the consistent dynamical processes associated with the ENSO-induced forcing, we examine the predictable patterns for the 300-hPa zonal winds.

Figure 12a shows the leading predictable pattern of DJF 300-hPa zonal winds. In the tropics, the pattern shows easterly anomalies in the eastern tropical Pacific Ocean and westerly anomalies in the tropical Atlantic Ocean, resembling a Gill-type response to ENSOinduced heating anomalies (Gill 1980; Jin and Hoskins 1995). In the Northern Hemisphere subtropics and midlatitudes, the pattern shows a strong dipole with strengthening of the subtropical jet and weakening of the midlatitude jet extending from the North Pacific across North America to the North Atlantic, reminiscent of the Pacific-North American teleconnection pattern (PNA) (Wallace and Gutzler 1981) in the upper troposphere jet field. The pattern in the South Pacific also shows a strong dipole with strengthening of the subtropical jet and weakening of the midlatitude jet, while a weak dipole equatorward shifting jet extends from the South Atlantic to the southern Indian Ocean. The APT value for this component is 17.9 months, and the fraction of global variance explained by this component is about $23.8 \%$. The spatial distribution of the fraction of variance explained by this component also shows strong geographic locations (e.g., the fraction is as 


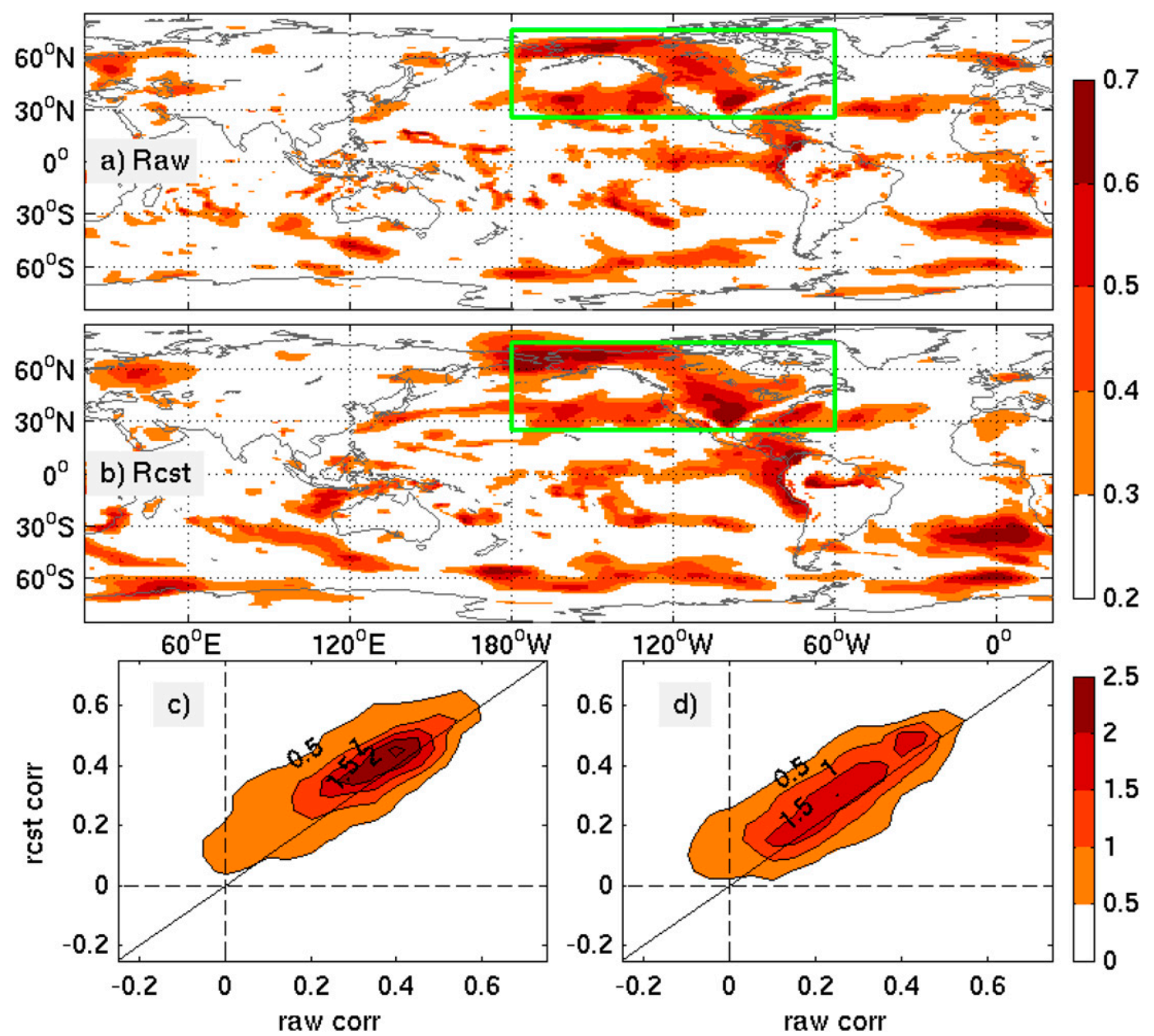

FIG. 9. Anomaly correlation coefficients (ACC) between the 1-month lead hindcasts and observations for the DJF season at lead 1 month for (a) the raw hindcasts and (b) the reconstructed hindcasts from the first three predictable components. Also shown is a scatterplot of the percentage of grid points over the North Pacific and North America region [green box in (a) and (b)] in each bin from -0.25 to 0.75 (interval of 0.05 ) for anomaly correlation coefficients in DJF for (c) lead time 0-4 months and (d) lead 5-9 months. Only ACC above 5\% significance level shown in (a) and (b).

much as $50 \%$ in the tropics and subtropics, and $30 \%$ in the extratropics of North America) (Fig. 12b).

The observed and hindcasted time series of the leading APT in DJF as a function of initialized years from 1982 to 2014 are shown in Fig. 12c for lead times of 1-5 and 6-10 months, respectively. The time series in observations is very strongly correlated with the observed Niño-3.4 index with a correlation coefficient of 0.96 , suggesting that this pattern is ENSO-related. The skill of predicting this 300 -hPa zonal wind pattern is almost equivalent to the skill of predicting ENSO itself. The second predictable pattern of the DJF 300-hPa zonal winds also exhibits a poleward shift and strengthening of the SH midlatitude jet (not shown), which is consistent with the $\mathrm{PrC} 2$ of the $\mathrm{SH}$ storm track.
Figure 13a shows the leading predictable pattern of the JAS 300-hPa zonal winds. In the tropics, the pattern also shows a similar Gill-type response wind pattern to ENSO-induced heating anomalies as the DJF pattern. In the subtropics and midlatitudes, the maximum loadings of the pattern locate in the South Pacific with strengthening of the subtropical jet and the weakening of midlatitude jet. The patterns in the South Atlantic and south Indian Ocean are generally of opposite sign to that in the South Pacific, although the associated amplitudes are much weaker. The zonal wind pattern is consistent with the observed wave train pattern associated with ENSO in the SH winter (Karoly 1989) and the observed Antarctic dipole mode associated with ENSO (Yuan 2004). The APT value for this component is 15.7 
Storm track prediction for 13-14 DJF

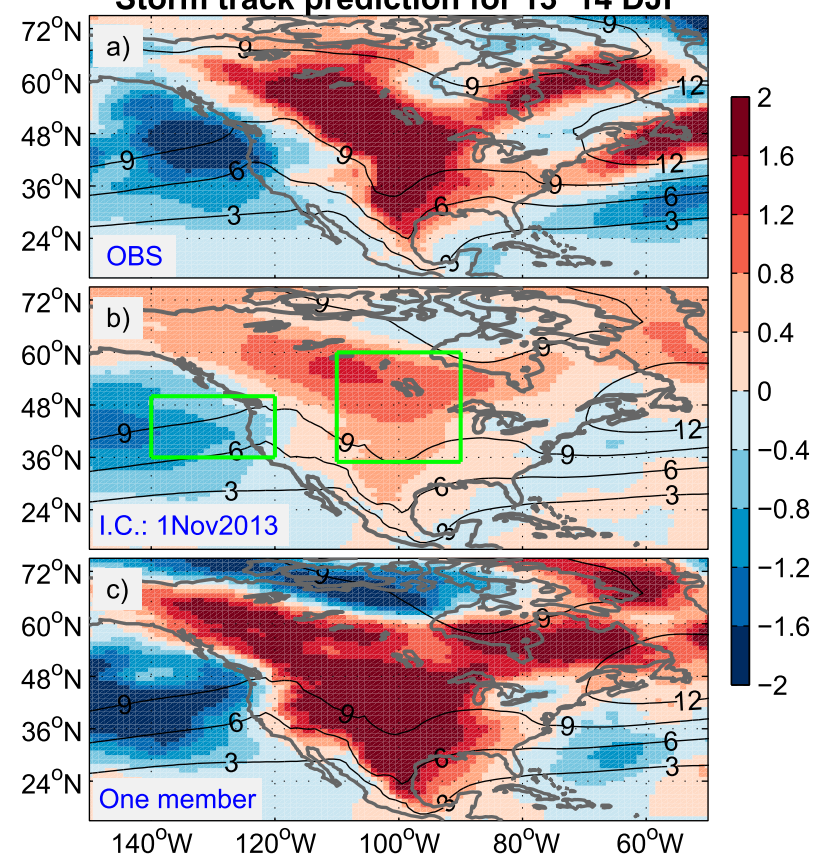

FIG. 10. (a) The observed storm-track anomalies (color shading) for the 2013/14 DJF season. (b) The ensemble mean and (c) one "best" member of the predicted storm-track anomalies initialized on 1 Nov 2013. The black contour denotes the climatological storm tracks. Units are hPa.

months, and the fraction of global variance explained by this component is about $15.3 \%$. This component explains as much as $50 \%$ in certain tropical and subtropical areas, and $30 \%$ in the South Pacific (Fig. 13b). Compared to the DJF season, the APT value and the fraction of global variance explained by $\mathrm{PrC} 1$ are consistently lower in JAS, suggesting the strong seasonal variations of the ENSO-teleconnected $300-\mathrm{hPa}$ zonal wind predictability.

The observed and hindcasted time series of the leading APT in JAS as a function of initialized years from 1982 to 2014 are shown in Fig. 13b for lead times of 1-5 and 6-10 months, respectively. Again, the observed time series is very strongly correlated with the observed Niño-3.4 index with the correlation coefficient of 0.91 (Fig. 13b), suggesting that this pattern is also strongly ENSO-related. The skill of predicting this $300-\mathrm{hPa}$ zonal wind pattern is generally comparable to the skill of predicting ENSO itself.

In summary, the leading predictable $300-\mathrm{hPa}$ zonal wind patterns are dynamically consistent with the leading storm-track patterns reported in section $4 \mathrm{~b}$ for both DJF and JAS seasons, and they are all related to ENSO. For instance, in DJF, the equatorward jet shift is accompanied by its storm-track shift in the North Pacific, and the jet weakening is associated with a storm

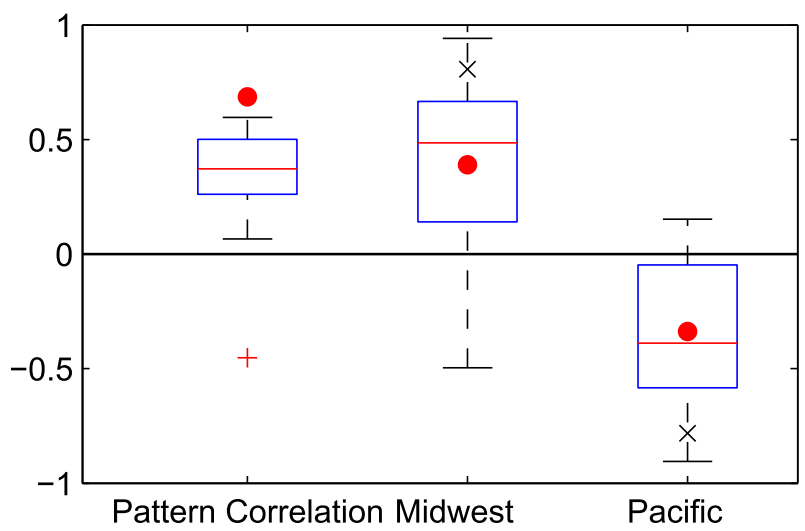

FIG. 11. The box and whisker plots for (left) the pattern correlation coefficients between each ensemble member and observed storm-track anomalies over the North Pacific and North American region $\left(25^{\circ}-70^{\circ} \mathrm{N}, 150^{\circ}-50^{\circ} \mathrm{W}\right)$, and the spatial mean storm-track anomalies of each ensemble member and ensemble mean for (middle) one region $\left(35^{\circ}-60^{\circ} \mathrm{N}, 110^{\circ}-90^{\circ} \mathrm{W}\right)$ over the North American Midwest and (right) another $\left(35^{\circ}-50^{\circ} \mathrm{N}, 140^{\circ}-120^{\circ} \mathrm{W}\right)$ in the North Pacific. The ensemble mean values are denoted as the red circles, and the observed values are denoted as the black crosses. The hindcast is the same as in Fig. 10.

reduction in the mid and high latitudes of North America; in JAS season, the jet weakening is consistent with a storm reduction in the zone between subtropical and polar front jets in the South Pacific.

\section{d. Impact on extreme events}

The increase (reduction) of seasonal storm tracks enhances (reduces) the weather disturbances (both cyclones and anticyclones), so the storm-track changes associated with ENSO are characterized by changes in second-moment statistics (e.g., width of distribution) of weather-relevant variables (e.g., SLP, temperature, surface winds, and precipitation). Since the ENSO-related storm-track patterns are to some extent predictable in the model, we expect the corresponding second-moment statistics changes to be predictable. We use the percentile statistics as a measure of the distribution. Here, we examine the 1st, 50th, and 99th percentile values of SLP, temperature, wind, and precipitation in the DJF season for 5-yr composites of El Niño (1982, 1986, 1991, 1997, and 2009) and La Niña (1988, 1999, 2000, 2007, and 2010) respectively. The year here refers to the year of the January.

We focus on the cross section line with maximum storm-track predictable signals that extends from northwestern Canada to the U.S. Midwest (Fig. 14a). The first, 50th, and 99th percentile values of SLP, calculated from the 6-hourly model and ERA-Interim data during the composite El Niño years and La Niña years along the cross section line, are shown in Fig. 14. The 

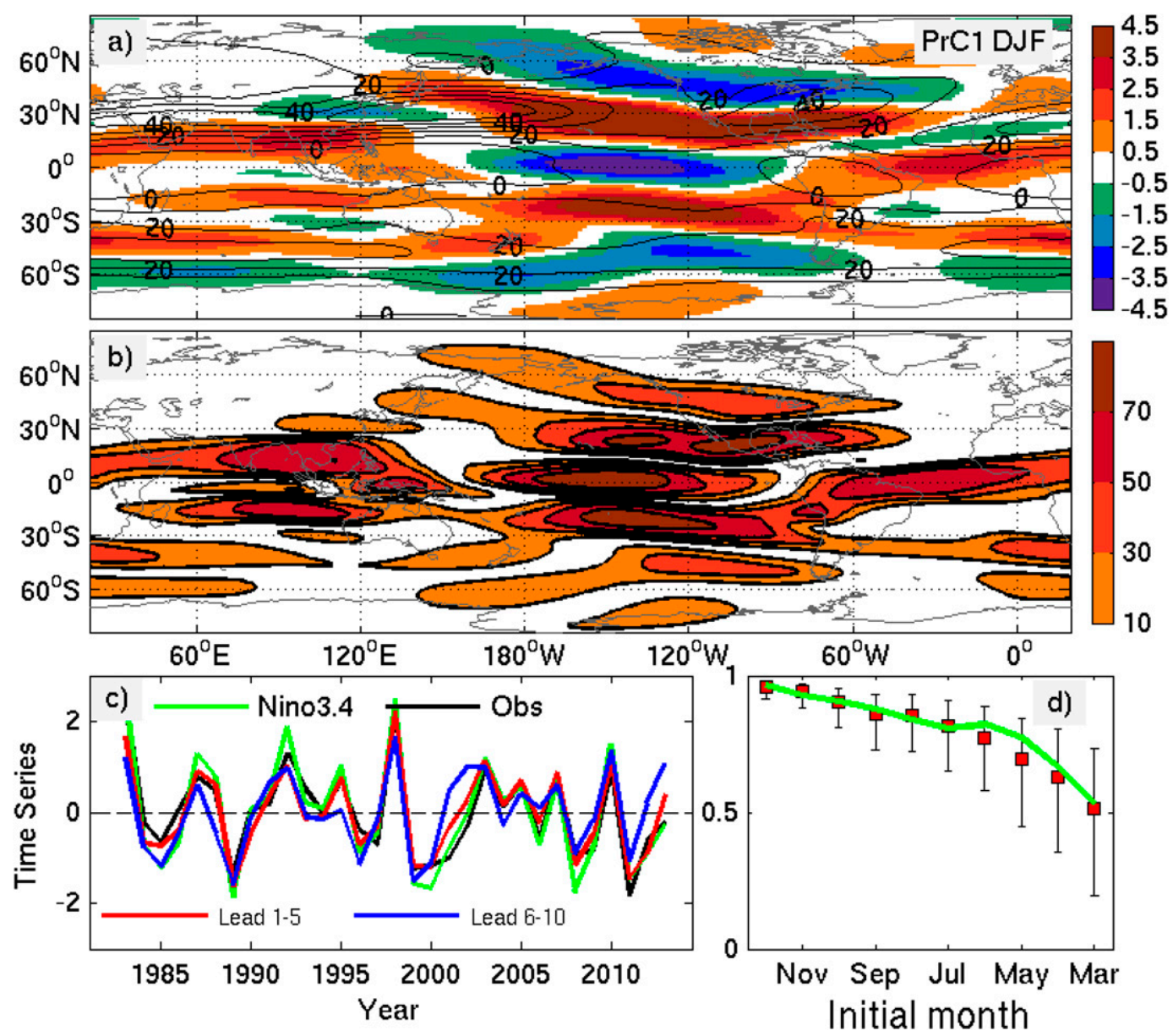

FIG. 12. (a) The spatial structure of the leading predictable component (color shading) that maximized the average predictability time of $300-\mathrm{hPa}$ zonal winds in the hindcasts for the DJF season, which is called PrC1. The black contour denotes the climatological $300-\mathrm{hPa}$ zonal winds $\left(\mathrm{in} \mathrm{m} \mathrm{s} \mathrm{s}^{-1}\right.$ ). The shading unit is $\mathrm{m} \mathrm{s}^{-1}$ per unit standard deviation. (b) Percent of variance of storm tracks explained by PrC1. (c) The ensemble mean time series of PrC1 averaged over lead time 0-4 months (red solid) and 5-9 months (blue solid) as a function of time, and the time series of the ERA-Interim data projected onto PrC1 (black solid). (d) The anomaly correlation coefficients (ACC) between forecasts and observations (red squares) and associated $95 \%$ error bars as a function of the forecast lead time. The green line denotes the ACC for the Niño-3.4 index.

model predicts larger (smaller) 99th and smaller (larger) first percentile values of SLP during La Niña (El Niño) years. The 99th percentile SLP values changing with the ENSO phases are in good agreement between observations and model simulations. The predicted 50th percentile values changing with ENSO agree with observations only in the western half of the cross section line, while the predicted first percentile values agree with observations only in the eastern half of the cross section line. The distribution width changes of SLP associated with ENSO tend to skew to the anticyclone extremes in both the ERA-Interim reanalysis and model hindcasts, especially in the western half of the cross section line. Note that the similar changes of extreme percentile values associated with ENSO phases were found in other short lead hindcasts (e.g., initialized later than 1 June of the composite years), and the changes are virtually indistinguishable for the hindcasts initialized earlier than 1 July of the composite years (not shown).

The similar percentile values for the 2-m air temperature $(\mathrm{T} 2 \mathrm{~m}), 10-\mathrm{m}$ wind speed $(\mathrm{W} 10 \mathrm{~m})$, and the daily precipitation are shown in Fig. 15. The model and observation agree well on the decreased (increased) 50th and first percentile values of T2m during La Niña (El Niño) years, while there is no agreement between the model and observation for the 99th percentile values changing with the ENSO phases. For W10m, there is a general agreement between model and observation on the increased (decreased) 50th and 99th percentile values during La Niña (El Niño) years, although the 

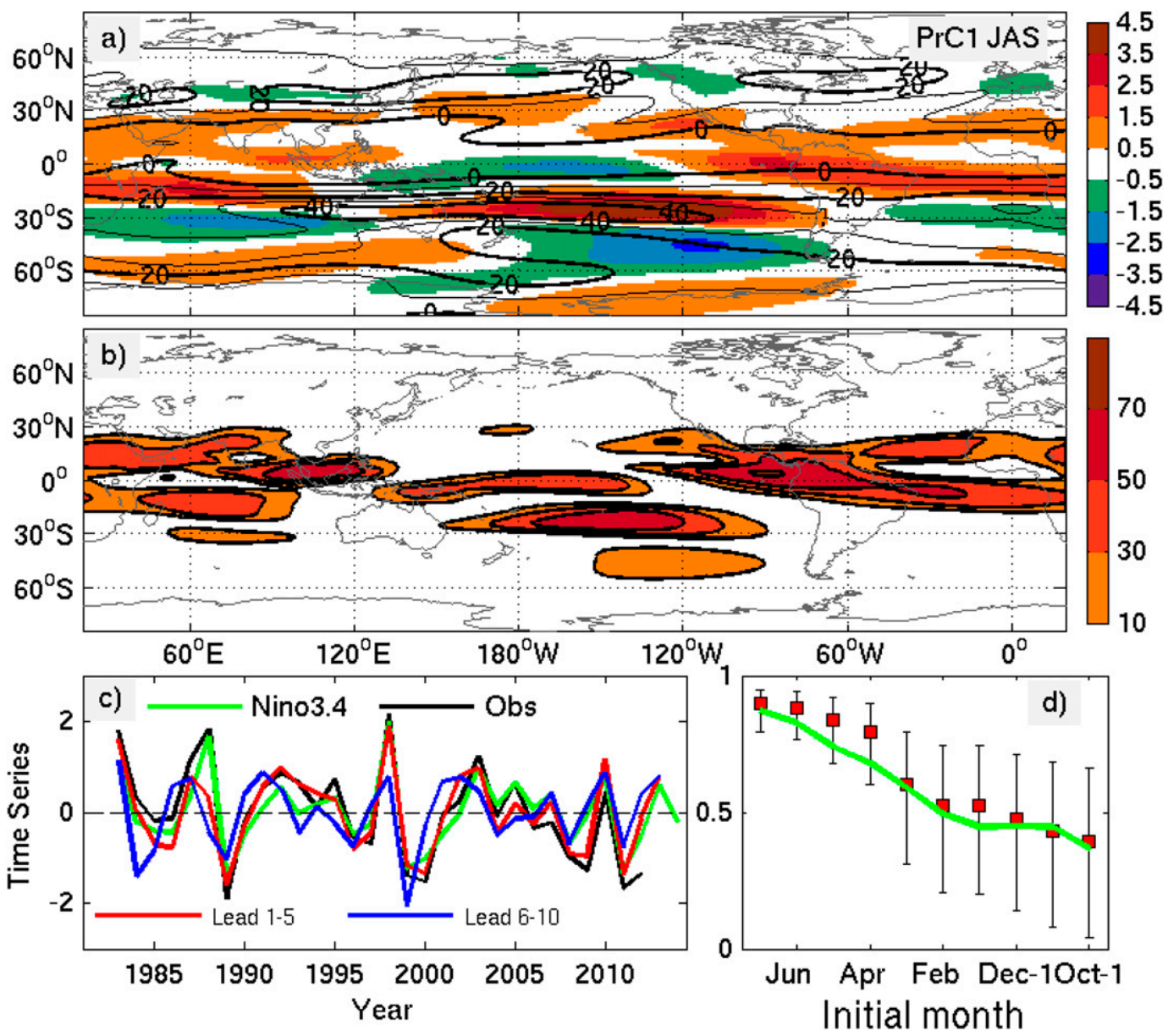

FIG. 13. As in Fig. 12, but for the JAS season.

contrast between the two phases of ENSO for 99th percentile values is weaker in observations. The daily precipitation's 99th percentile value changes associated with ENSO phases are in low agreement between model and observation, although the simulated daily precipitation shows a very slight coherent increased (decreased) 99th percentile values during La Niña (El Niño) years. Interestingly, model and observations generally agree on more rainy days during La Niña years than El Niño years (Fig. 16).

The percentile value changes of the meteorological variables associated with the ENSO phases are dynamically consistent with the corresponding predictable stormtrack changes over North America. During La Niña years, enhanced storm tracks correspond to increased anticyclones and cyclones over North America, leading to a broader distribution width of SLP (i.e., larger 99th percentile values and smaller first percentile values). The opposite is true for El Niño years. The distribution width changes of SLP tend to skew to the anticyclone extremes in both the ERA-Interim reanalysis and model hindcasts.
Consequently, the distribution width changes of $\mathrm{T} 2 \mathrm{~m}$ skew to the cold temperature extremes, since an extreme cold event is generally linked to an extreme anticyclone with a cold front on its leading edge. The model also predicts coherent $10-\mathrm{m}$ wind speed, daily precipitation extremes, and rainy day ratio changes associated with ENSO. Thus, the high-resolution model is capable of providing the extreme-related second-order statistical information beyond a single mean for seasonal forecasts.

\section{Conclusions}

The seasonal predictability of extratropical storm tracks in GFDL's high-resolution seasonal hindcasts has been investigated using APT analysis. For both DJF and JAS seasons, the leading predictable storm-track patterns are ENSO-related. The positive phase of the DJF pattern generally shows an equatorward shift of the North Pacific and North Atlantic storm tracks, as well as of the South Atlantic and Indian Ocean storm tracks, and weakening of the North America and the South 

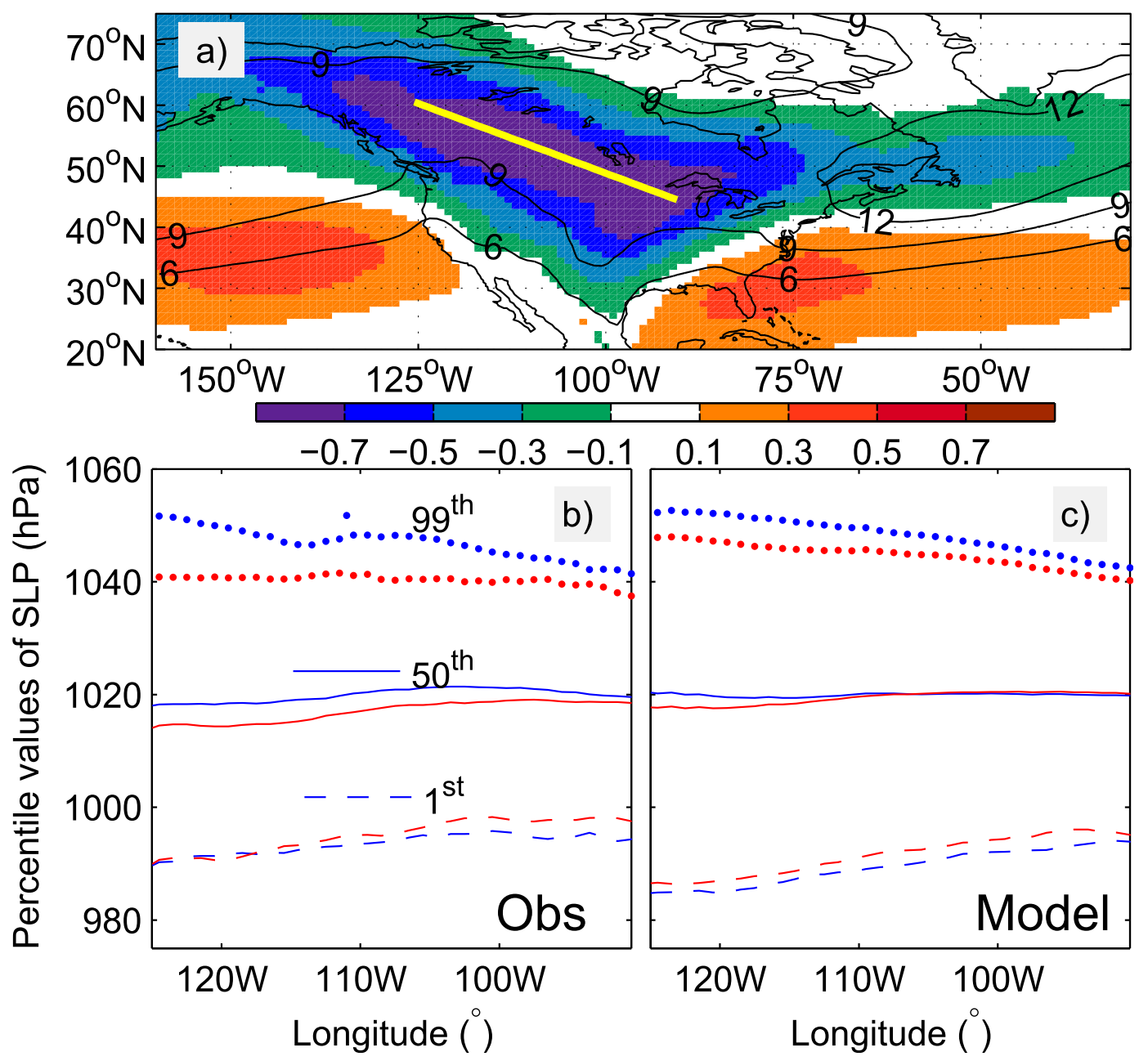

FIG. 14. (a) The spatial structure of the leading predictable component (color shading) that maximized the average predictability time of storm tracks in the hindcasts for the DJF season. The black contour denotes the climatological storm tracks (in hPa). Also shown are the 1st (dots), 50th (solid), and 99th (dashed) percentile values of 6-hourly SLP in the composite El Niño years (red) and La Niña years (blue) for (b) observation and (c) model along the cross section line with maximum storm-track predictable signals [the thick line in (a)]. Note that the hindcasts shown here were initialized on 1 December of the composite years.

Pacific storm tracks. Over 1980-2013, the whole pattern is retrospectively predictable up to 9 months in advance at the $5 \%$ significance level. The positive phase of the JAS pattern is characterized by a poleward shift of the South Atlantic storm tracks, a dipole structure with weakening of storm-track activity between $40^{\circ}$ and $60^{\circ} \mathrm{S}$ and strengthening between $30^{\circ}$ and $40^{\circ} \mathrm{S}$ in the South Pacific, and strengthening of storm tracks in the western Antarctic continent. The retrospective predictive skill of the JAS pattern is generally lower than that of the DJF pattern.

The positive phase of the second predictable component for the DJF seasonal hindcasts generally shows a poleward shift and strengthening of the Southern Hemisphere storm tracks and weakening of the North Atlantic storm tracks. The second mode's time series is dominated by a multidecadal trend in both hindcasts and observations, corresponding to the response to changes in external forcing and AMO phases. The second predictable component for the JAS season generally shows a band of increased storm activity between $30^{\circ}$ and $70^{\circ} \mathrm{S}$ in the South Atlantic, south Indian Ocean, and the western part of the South Pacific, and the associated time series is trendlike, although the trend signal is weaker than during the DJF season. The significant role of radiative forcing to the seasonal prediction is also seen in the land surface temperature predictability using the same model (Jia et al. 2015), suggesting that seasonal climate prediction is a joint initial-boundary value problem.

The ENSO-related leading predictable storm-track component is dynamically consistent with the leading 

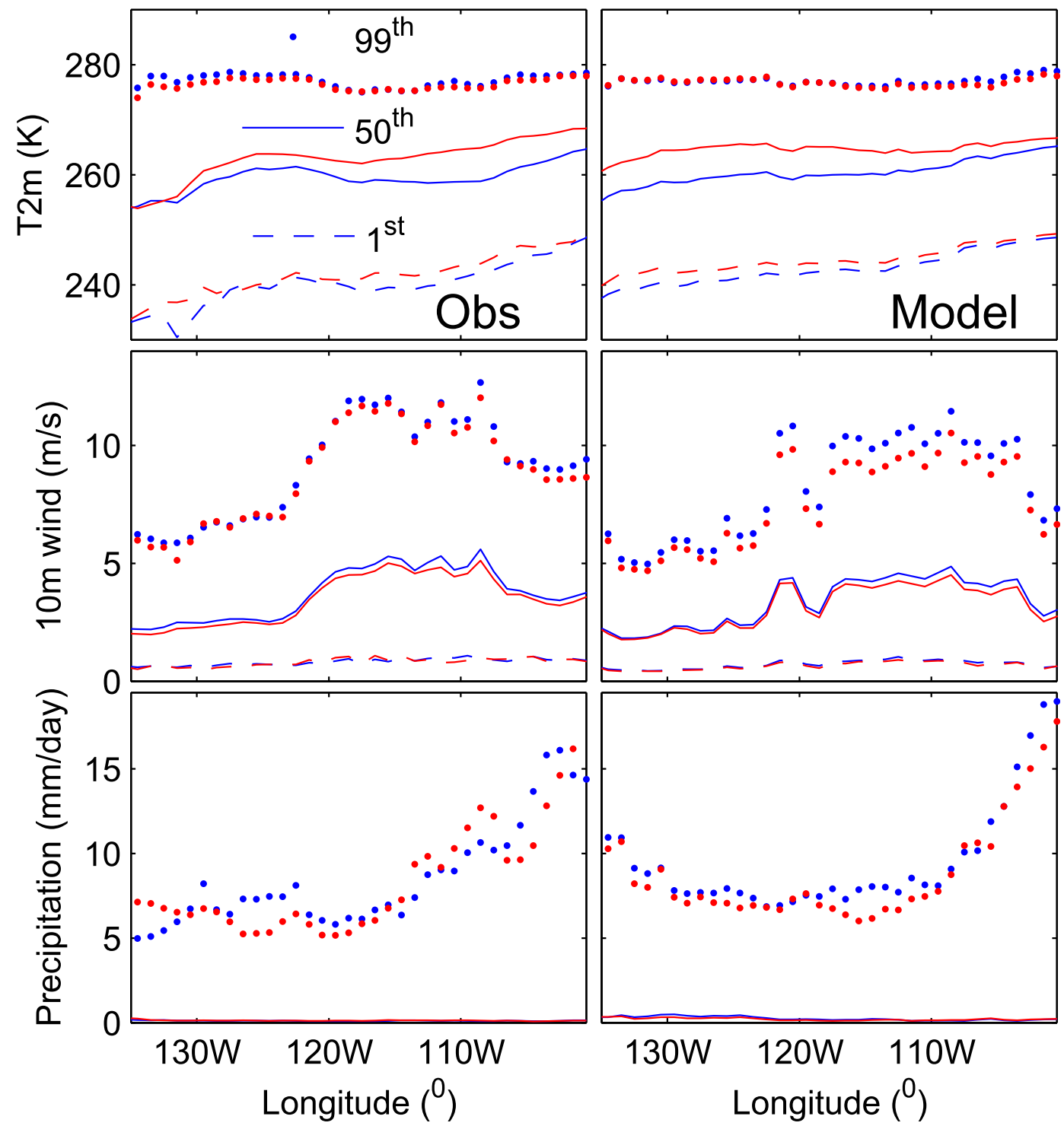

FIG. 15. The 1st (dots), 50th (solid), and 99th (dashed) percentile values of (top) 6-hourly 2-m air temperature, (middle) 10-m wind speed, and (bottom) daily precipitation in the composite El Niño years (red) and La Niña years (blue) for (left) observation and (right) model in the cross section line with maximum storm-track predictable signals (the heavy line in the upper panel of Fig. 14). Note the hindcasts shown here were initialized on 1 December of the composite years.

predictable component of the $300-\mathrm{hPa}$ zonal wind during both DJF and JAS. For example, the equatorward jet shift in the DJF predictable mode is accompanied by a similar storm-track shift in the North Pacific, while the jet weakening is associated with the storm reduction in the mid and high latitudes of North America; in JAS, the jet weakening has a storm reduction in the zone between the subtropical and polar front jets in the South Pacific.

The fraction of global variance explained by each predictable component for both seasons is generally lower than about $10 \%$; however, the predictable components can explain a substantially large amount of the variance over broad geographic regions. For example, the leading predictable component of storm tracks in DJF explains as much as $35 \%$ of the variance over much of North America.

The FLOR model was able to retrospectively predict the meteorological variable extreme changes associated with ENSO over the region with the maximum predictable storm-track signals in North America (section 4d). During La Niña (El Niño) years, enhanced (reduced) storm tracks correspond to increased (decreased) 

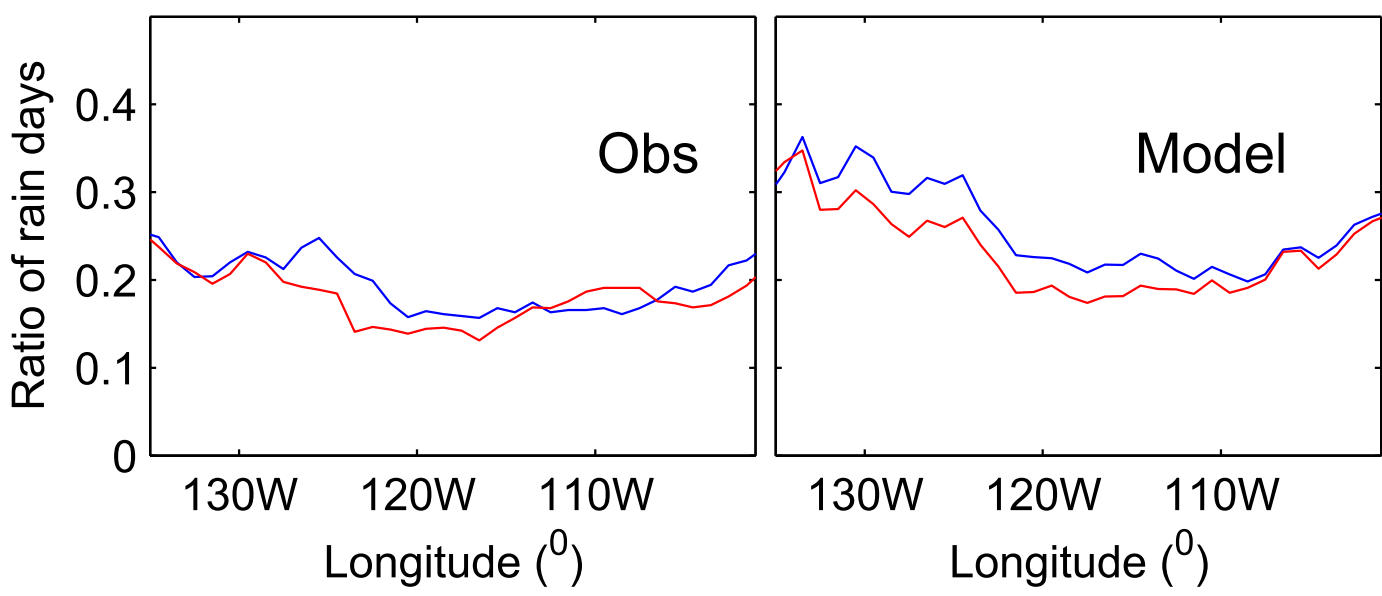

FIG. 16. The rainy day ratio during the composite El Niño years (red) and La Niña years (blue) for (left) observation and (right) model in the cross section line with maximum storm-track predictable signals (the heavy line in the upper panel in Fig. 14).

anticyclones and cyclones, which lead to a broader (narrower) distribution width of SLP, that is, larger (smaller) 99th percentile values and smaller (larger) first percentile values. The changes in distribution width of SLP tend to skew to the anticyclone extremes in both the ERA-Interim reanalysis and model hindcasts. Consequently, the shape of the probability density of $\mathrm{T} 2 \mathrm{~m}$ changes so as to skew toward cold temperature extremes, since an extreme cold event is generally linked to an extreme anticyclone. The model also predicts coherent shifts in the statistics of extremes of 10-m wind speed, daily precipitation extremes, and rainy day ratio changes associated with ENSO. Hence, as it has been able to do in the tropics when focusing on tropical cyclones (Vecchi et al. 2014), this high-resolution model is capable of providing higher-order statistical information related to extremes, thus enriching the seasonal forecast products for the research community and decision makers beyond the seasonal mean.

The analyzed seasonal predictability of extratropical storm tracks may be subject to the forecast model and the initialization methodology used. Further improvements in predictive skill of extratropical storm tracks are expected when the seasonal prediction system directly uses FLOR as the data assimilation model and/or the model bias is reduced.

Acknowledgments. We thank Lucas Harris and Liping Zhang for helpful reviews of an earlier draft, and Ben Kirtman and two anonymous reviewers for constructive comments that helped to improve the manuscript. We thank Isaac Held for insightful discussions about this research which lead to improvements and clarifications. This research was supported by the Visiting Scientist Program at the National Oceanic and Atmospheric
Administration's Geophysical Fluid Dynamics Laboratory, administered by the University Corporation for Atmospheric Research. This research was partly supported by the Disaster Recovery Act of 2013.

\section{REFERENCES}

Barnston, A. G., M. K. Tippett, M. L. L'Heureux, S. Li, and D. G. DeWitt, 2012: Skill of real-time seasonal ENSO model predictions during 2002-11: Is our capability increasing? Bull. Amer. Meteor. Soc., 93, 631-651, doi:10.1175/BAMS-D-11-00111.1.

Bjerknes, J., 1969: Atmospheric teleconnections from the equatorial Pacific. Mon. Wea. Rev., 97, 163-172, doi:10.1175/ 1520-0493(1969)097<0163:ATFTEP >2.3.CO;2.

Branstator, G., 1995: Organization of storm track anomalies by recurring low-frequency circulation anomalies. J. Atmos. Sci., 52, 207-226, doi:10.1175/1520-0469(1995)052<0207: OOSTAB $>2.0 . \mathrm{CO} ; 2$.

Cai, M., and M. Mak, 1990: Symbiotic relation between planetary and synoptic-scale waves. J. Atmos. Sci., 47, 2953-2968, doi:10.1175/ 1520-0469(1990)047<2953:SRBPAS>2.0.CO;2.

Chang, E. K. M., and Y. Fu, 2002: Interdecadal variations in Northern Hemisphere winter storm track intensity. J. Climate, 15, 642-658, doi:10.1175/1520-0442(2002)015<0642:IVINHW>2.0.CO;2.

— S. Lee, and K. L. Swanson, 2002: Storm track dynamics. J. Climate, 15, 2163-2183, doi:10.1175/1520-0442(2002)015<02163: $\mathrm{STD}>2.0 . \mathrm{CO} ; 2$.

—, Y. Guo, and X. Xia, 2012: CMIP5 multimodel ensemble projection of storm track change under global warming. J. Geophys. Res., 117, D23118, doi:10.1029/2012JD018578.

,,--- , and M. Zheng, 2013: Storm-track activity in IPCC AR4/CMIP3 model simulations. J. Climate, 26, 246260, doi:10.1175/JCLI-D-11-00707.1.

Chang, Y.-S., S. Zhang, A. Rosati, T. L. Delworth, and W. F. Stern, 2013: An assessment of oceanic variability for 1960-2010 from the GFDL ensemble coupled data assimilation. Climate Dyn., 40, 775-803, doi:10.1007/s00382-012-1412-2.

Dee, D. P., and Coauthors, 2011: The ERA-Interim reanalysis: Configuration and performance of the data assimilation system. Quart. J. Roy. Meteor. Soc., 137, 553-597, doi:10.1002/qj.828. 
DelSole, T., and M. K. Tippett, 2009a: Average predictability time. Part I: Theory. J. Atmos. Sci., 66, 1172-1187, doi:10.1175/ 2008JAS2868.1.

$\longrightarrow$, and —, 2009b: Average predictability time. Part II: Seamless diagnosis of predictability on multiple time scales. J. Atmos. Sci., 66, 1188-1204, doi:10.1175/2008JAS2869.1.

,-- , and J. Shukla, 2011: A significant component of unforced multidecadal variability in the recent acceleration of global warming. J. Climate, 24, 909-926, doi:10.1175/ 2010JCLI3659.1.

Delworth, T. L., and Coauthors, 2006: GFDL's CM2 global coupled climate models. Part I: Formulation and simulation characteristics. J. Climate, 19, 643-674, doi:10.1175/ JCLI3629.1.

_ and Coauthors, 2012: Simulated climate and climate change in the GFDL CM2.5 high-resolution coupled climate model. J. Climate, 25, 2755-2781, doi:10.1175/JCLI-D-11-00316.1.

Eichler, T., and W. Higgins, 2006: Climatology and ENSO-related variability of North American extratropical cyclone activity. J. Climate, 19, 2076-2093, doi:10.1175/JCLI3725.1.

Farneti, R., T. L. Delworth, A. J. Rosati, S. M. Griffies, and F. Zeng, 2010: The role of mesoscale eddies in the rectification of the Southern Ocean response to climate change. J. Phys. Oceanogr., 40, 1539-1557, doi:10.1175/2010JPO4353.1.

Gill, A. E., 1980: Some simple solutions for heat-induced tropical circulations. Quart. J. Roy. Meteor. Soc., 106, 447-462, doi:10.1002/qj.49710644905.

Held, I. M., S. W. Lyons, and S. Nigam, 1989: Transients and the extratropical response to El Niño. J. Atmos. Sci., 46, 163-174, doi:10.1175/1520-0469(1989)046<0163:TATERT>2.0.CO;2.

Jia, L., and Coauthors, 2015: Improved Seasonal Prediction of Temperature and Precipitation over Land in a HighResolution GFDL Climate Model. J. Climate, 28, 2044-2062, doi:10.1175/JCLI-D-14-00112.1.

Jin, F., and B. J. Hoskins, 1995: The direct response to tropical heating in a baroclinic atmosphere. J. Atmos. Sci., 52, 307-319, doi:10.1175/1520-0469(1995)052<0307:TDRTTH > 2.0.CO;2.

Karoly, D. J., 1989: Southern Hemisphere circulation features associated with El Niño-Southern Oscillation events. J. Climate, 2, 1239-1252, doi:10.1175/1520-0442(1989)002<1239: SHCFAW $>2.0 . \mathrm{CO} ; 2$.

Klein Tank, A. M. G., F. W. Zwiers, and X. Zhang, 2009: Guidelines on analysis of extremes in a changing climate in support of informed decisions for adaption. WMO-TD 1500, WCDMP-No. 72, 56 pp.

Lau, N.-C., 1988: Variability of the observed midlatitude storm tracks in relation to low-frequency changes in the circulation pattern. J. Atmos. Sci., 45, 2718-2743, doi:10.1175/ 1520-0469(1988)045<2718:VOTOMS $>2.0$. CO 2 .

Merryfield, W. J., and Coauthors, 2013: The Canadian Seasonal to Interannual Prediction System. Part I: Models and initialization. Mon. Wea. Rev., 141, 2910-2945, doi:10.1175/MWR-D-12-00216.1.

Msadek, R., G. A. Vecchi, M. Winton, and R. G. Gudgel, 2014a: Importance of initial conditions in seasonal predictions of Arctic sea ice extent. Geophys. Res. Lett., 41, 5208-5215, doi:10.1002/ 2014GL060799.

— , and Coauthors, 2014b: Predicting a decadal shift in North Atlantic climate variability using the GFDL forecast system. J. Climate, 27, 6472-6496, doi:10.1175/JCLI-D-13-00476.1.
Rayner, N. A., D. E. Parker, E. B. Horton, C. K. Folland, L. V. Alexander, D. P. Rowell, and A. Kaplan, 2003: Global analyses of sea surface temperature, sea ice, and night marine air temperature since the late nineteenth century. J. Geophys. Res., 108, 4407, doi:10.1029/2002JD002670.

Saha, S., and Coauthors, 2006: The NCEP Climate Forecast System. J. Climate, 19, 3483-3517, doi:10.1175/JCLI3812.1.

, and Coauthors, 2014: The NCEP Climate Forecast System version 2. J. Climate, 27, 2185-2208, doi:10.1175/JCLI-D-12-00823.1.

Stockdale, T. N., and Coauthors, 2011: ECMWF Seasonal Forecast System 3 and its prediction of sea surface temperature. Climate Dyn., 37, 455-471, doi:10.1007/s00382-010-0947-3.

Straus, D. M., and J. Shukla, 1997: Variations of midlatitude transient dynamics associated with ENSO. J. Atmos. Sci., 54, 777-790, doi:10.1175/1520-0469(1997)054<0777:VOMTDA>2.0.CO;2.

Vecchi, G. A., and Coauthors, 2013: Multiyear predictions of North Atlantic hurricane frequency: Promise and limitations. J. Climate, 26, 5337-5357, doi:10.1175/JCLI-D-12-00464.1.

— tropical cyclone activity. J. Climate, 27, 7994-8016, doi:10.1175/ JCLI-D-14-00158.1.

Wallace, J. M., and D. S. Gutzler, 1981: Teleconnections in the geopotential height field during Northern Hemisphere winter. Mon. Wea. Rev., 109, 784-812, doi:10.1175/1520-0493(1981)109<0784: TITGHF $>2.0 . \mathrm{CO} ; 2$.

- G. Lim, and M. Blackmon, 1988: Relationship between cyclone tracks, anticyclone tracks and baroclinic waveguides. J. Atmos. Sci., 45, 439-462, doi:10.1175/1520-0469(1988)045<0439: RBCTAT $>2.0 . \mathrm{CO} ; 2$.

Yang, X., and E. K. M. Chang, 2006: Variability of the Southern Hemisphere winter split flow: A case of two-way reinforcement between mean flow and eddy anomalies. J. Atmos. Sci., 63, 634650, doi:10.1175/JAS3643.1.

_, and — 2007: Eddy-zonal flow feedback in the Southern Hemisphere winter and summer. J. Atmos. Sci., 64, 3091-3112, doi:10.1175/JAS4005.1

, and T. DelSole, 2012: Systematic comparison of ENSO teleconnection patterns between models and observations. J. Climate, 25, 425-446, doi:10.1175/JCLI-D-11-00175.1. , and Coauthors, 2013: A predictable AMO-like pattern in GFDL's coupled initialization and decadal forecasting system. J. Climate, 26, 650-661, doi:10.1175/JCLI-D-12-00231.1.

Yuan, X., 2004: ENSO-related impacts on Antarctic sea ice: A synthesis of phenomenon and mechanisms. Antarct. Sci., 16, 415-425, doi:10.1017/S0954102004002238.

Zhang, R., and T. L. Delworth, 2007: Impact of the Atlantic multidecadal oscillation on North Pacific climate variability. Geophys. Res. Lett., 34, L23708, doi:10.1029/2007GL031601.

Zhang, S., and A. Rosati, 2010: An inflated ensemble filter for ocean data assimilation with a biased coupled GCM. Mon. Wea. Rev., 138, 3905-3931, doi:10.1175/2010MWR3326.1.

—, M. J. Harrison, A. Rosati, and A. T. Wittenberg, 2007: System design and evaluation of coupled ensemble data assimilation for global oceanic climate studies. Mon. Wea. Rev., 135, 35413564, doi:10.1175/MWR3466.1.

Zhang, Y., and I. M. Held, 1999: A linear stochastic model of a GCM's midlatitude storm tracks. J. Atmos. Sci., 56, 34163435, doi:10.1175/1520-0469(1999)056<3416:ALSMOA >2.0. $\mathrm{CO} ; 2$. 